\title{
Does Agency Funding Affect Decisionmaking?: An Empirical Assessment of the PTO's Granting Patterns
}

\author{
Michael D. Frakes* \\ Melissa F. Wasserman **
}

INTRODUCTION

I. ThE PTO's FINANCIAL INCENTIVES AND ITS

OBJECTIVES

A. The PTO's Budget Process and Its Possible

Financial Incentives to Grant Patents ..................... 76

B. The PTO's Objectives ....................................... 80

1. Self-Interested Bureaucrat....................... 80

2. Benevolent-but-Resource-Constrained

Bureaucrat

II. THE DifFERENTIAL IMPACT OF THE AGENCY'S

FINANCIAL INCENTIVES .......................................... 85

A. $\quad$ Renewal Rates.............................................. 88

* Assistant Professor of Law \& Director of Law and Economics Program, Cornell Law School. J.D., Ph.D.

** Assistant Professor of Law \& Richard W. and Marie L. Corman Scholar, University of Illinois College of Law. J.D., Ph.D.

The work was funded in part by University of Illinois at Urbana Champaign Research Board, Award 12088. We thank David Abrams, Michael Burstein, Michael Carrier, Daniel Chen, I. Glenn Cohen, Kevin Collins, Dennis Crouch, Peter DiCola, Michael Dorf, Rochelle Dreyfuss, Rebecca Eisenberg, Einer Elhauge, John Golden, Stuart Graham, Valerie Hans, Michael Heise, Paul Heald, Daniel Ho, David Hyman, Jay Kesan, Bob Lawless, Mark Lemley, Oskar Liivak, Jonathan Masur, Michael Meurer, Joseph Miller, Arti Rai, Benjamin Roin, Bhaven Sampat, David Schwartz, Sean Seymore, Bruno van Pottelsberghe de la Potterie, three anonymous reviewers, and the participants at the 5th Annual Junior Scholars in Intellectual Property Workshop, American Law \& Economics Association 2012 Annual Meeting, Cardozo IP Series, PatCon2, University of Illinois Faculty Retreat, Works-in-Progress Intellectual Property Colloquium 2012, IP Speaker Series at George Washington Law School, Midwestern Law \& Economics Association 2012 Annual Meeting, 7th Annual Conference on Empirical Legal Studies, Patent Statistics for Decision Makers 2012, and faculty presentation at Northwestern Law School for useful comments. 
1. The Self-Interested, Budget-Maximizing PTO. 89

2. The Benevolent-but-ResourcedConstrained PTO. 89

B. Entity Size ................................................... 91

1. The Self-Interested, Budget-Maximizing PTO.

2. The Benevolent-but-Resourced-

Constrained PTO.

III. DATA AND METHODOLOGY .............................................. 92

A. $\quad$ Data Sources and Key Variables ......................... 92

B. Methodology.................................................. 96

1. Difference-in-Difference Analysis................ 96

2. Financial-Sustainability Analysis ............... 99

IV. RESULTS ............................................................ 101

A. Difference-in-Difference Results: Renewal-Rate

Specifications ................................................ 102

1. Primary Difference-in-Difference Results ... 102

2. Sustainability-Interaction Results ............. 105

B. Difference-in-Difference Results: Entity-Size Specifications ............................................... 107

1. Primary Difference-in-Difference Results ... 107

2. Sustainability-Interaction Results .............. 109

C. Interactions with Fee-Diversion Policy.................. 109

D. Dynamic Difference-in-Difference Regression

Results ........................................................ 110

E. Robustness / Specification Checks ...................... 115

F. $\quad$ Results Summary and Implications .................... 118

V. IMPLICATIONS AND REDUCING THE PTO's FINANCIAL INCENTIVE TO GRANT PATENTS ...................................... 119

A. Implications of the America Invents Act ................ 120

B. Reducing the PTO's Financial Incentives to

Grant Patents................................................ 121

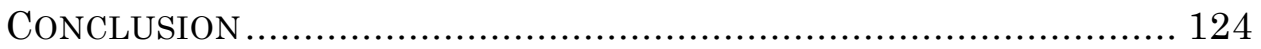

\section{INTRODUCTION}

In 1991, Congress changed the mechanism by which the United States Patent and Trademark Office ("PTO") was funded. The result was that the Agency, whose principal task is to determine whether an invention merits the reward of a patent, became almost entirely 
funded through user fees. ${ }^{1}$ Since 1991, the PTO's budget has largely been derived from patent examination and post-allowance fees. ${ }^{2}$ While patent processing comprises the majority of the Agency's operational expenses, patent examination fees cover less than one-third of the examination costs. ${ }^{3}$ As a result, the Agency is heavily dependent on post-allowance fees-fees the PTO only collects when it grants a patent-to fund its operations. This congressionally set fee structure creates a possible financial incentive for the PTO to grant patents, although the extent to which the Agency will act on this incentive depends both on the PTO's objectives and its needs. Thus, the 1991 variation in the law affords the opportunity to explore an important issue in administrative law-the relationship between agency funding and agency decisionmaking - and an important issue in patent lawwhether the PTO is biased toward issuing patents.

To the best of our knowledge, this Article undertakes the first attempt to causally investigate the influence of the PTO's funding on the Agency's decisionmaking (i.e., causal in the sense of statistically ruling out other potentially confounding factors). ${ }^{4}$ Through this causal investigation, it also builds upon those studies that have attemptedalbeit, more indirectly than the present study-to challenge the hypothesis that the PTO's granting decisions are solely guided by the nonbiased application of patentability standards. ${ }^{5}$ To this extent, we

1. Omnibus Budget Reconciliation Act of 1990, Pub. L. No. 101-508, § 10101, 104 Stat. 1388.

2. See, e.g., U.S. Patent \& Trademark Office, Performance And Accountability REPORT, FISCAL YEAR 2010, at 55 (2010) [hereinafter 2010 PERFORMANCE AND ACCOUNTABILITY REPORT], available at http://www.uspto.gov/about/stratplan/ar/2010/USPTOFY2010PAR.pdf (stating that approximately $85 \%$ of total patent income comes from maintenance fees; fees for initial application filing, search, and examination; and issue fees).

3. See id. at 55, 57 (showing that although filing, search, and examination fees amount to only $28.7 \%$ of patent revenue, the "USPTO directs maximum resources to the priority functions of patent and trademark examination").

4. One study by Deepak Hegde has theorized that the PTO's appropriation process (but not the fee schedule) affects patent backlog and patent pendency. However, unlike our analysis, Hegde's analysis, which relies upon graphical time series evidence, was not designed to statistically identify (i.e., isolate) the actual relationship between the Agency's funding and outcome of interest. Moreover, Hegde did not explore how the PTO's fee schedule affects patent outcomes nor did he explore how the PTO's appropriation process affects the Agency's decision to grant a patent. Deepak Hegde, Funding and Performance at the US Patent and Trademark Office, 30 NATURE BIOTECHNOLOGY 148 (2012).

5. A number of scholars have set forth evidence that indirectly (noncausally) bears on the question of whether the U.S. PTO is biased in its decisionmaking. For instance, scholars have compared the growth of patent families-patents that are directed to the same underlying inventions that are filed in multiple countries-that originated in the United States with successful applications in the United States by U.S. inventors and found the latter to have grown over twice as much as the former. They have reasoned that this difference supports declining 
set forth a theoretical model that predicts that, under certain Agency objectives, particular elements of the PTO's fee structure create incentives for the PTO to grant additional patents. Using a rich database of previously unavailable patent data, we then empirically test the predictions of this model by comparing the Agency's granting patterns before and after the period the PTO became fully user-fee funded. ${ }^{6}$

Our results suggest that the Agency's fee schedule biases the PTO toward granting patents. For instance, with respect to those types of patents for which the PTO is likely to profit the most from granting, we estimate a relatively stronger sensitivity to the PTO's funding structure. More specifically, our findings suggest the PTO is preferentially granting patents on technologies with high renewal rates and patents filed by large entities, as the PTO stands to earn the most revenue by granting additional patents of these types. Furthermore, we also find that these distortions are more likely to occur when markers indicative of an underfunded PTO are present. As such, a more general implication of this analysis is that the PTO does not appear to seek a universal expansion of its budget. Rather, the evidence is more consistent with a view that distortions in the PTO's granting patterns are more likely to occur when the Agency is financially constrained.

Our findings have broad implications for both policy and theory. Regarding social welfare policy, our results are discouraging, as they suggest that the PTO's financial incentives, and not solely the merits of the invention, may in part be driving patentability decisions. Standard economic theory predicts that distortions in the PTO's granting behavior may result in substantial harm to society. While patents attempt to push society toward an optimal level of innovation by providing inventors with a mechanism to recoup their research and development expenses, they do so only at a cost-consumers pay

standards of the U.S. PTO, conceivably as a result of internal biases within the PTO. See, e.g., ADAM B. JAFFE \& JOSH LERNER, INNOVATION AND ITS DisCONTENTS 136-38, 142-43 (2004). Other scholars have put forth indirect evidence of a PTO bias by suggesting that the decisions of a certain group of examiners may be driven, in part, by considerations other than patentability standards. See generally Mark Lemley \& Bhaven Sampat, Examiner Characteristics and the Patent Office Outcomes, 94 REV. ECON. \& STAT. 817 (2012) (finding that more experienced examiners cite less prior art and are more likely to grant patents). While these studies provide valuable information, they have not been designed to causally identify a PTO bias, as we attempt to do in this Article. For instance, the Jaffe and Lerner analysis, while indeed suggestive of a number of possible biases, is not designed to statistically identify any particular bias as being responsible for the observed decline in patentability standards within the United States.

6. Details on the database are provided in Part III infra. 
higher prices and have less access to the patented invention. ${ }^{7}$ A PTO that is applying the patentability standards in a patent-protective manner is likely to be routinely granting patents on inventions that were either already known or represent only a trivial advancement over the existing scientific knowledge. ${ }^{8}$ As a result, a grant-biased PTO is likely to systematically issue patents that end up imposing significant costs on society without bestowing the commensurate benefits of innovation. ${ }^{9}$

Our results are also relevant to the ongoing policy debate in Congress and elsewhere on how best to fix the "broken" patent system. ${ }^{10}$ Criticism of the patent system has largely coalesced around one charge: the PTO permits too many invalid patents to issue, which unnecessarily drains consumer welfare. ${ }^{11}$ Both the Supreme Court's renewed interest in substantive patent law and the enactment of the America Invents Act, which represents the first major overhaul of the patent system in over sixty years, were driven in part by this

7. See William D. Nordhaus, Invention, Growth, and Welfare: A Theoretical TReatment of TEChNological Change 76 (1969) (explaining the need for finding the optimal patent length, because the longer a patent lasts, the greater the social cost of that patent due to inefficiencies caused by monopoly of information); Ian Ayres \& Gideon Parchomovsky, Tradable Patent Rights, 60 STAN. L. REV. 863, 867 (2000) (discussing the costs of "patent thickets"); Keith Leffler \& Christofer Leffler, Efficiency Trade-offs in Patent Litigation Settlements: Analysis Gone Astray?, 39 U.S.F. L. REV. 33, 33 (2004) (stating that the "static inefficiency" caused by valuable patents causes consumer welfare to suffer due to high prices).

8. Not surprisingly, the patentability standards reflect a careful balance between encouraging innovation and drains on consumer welfare. In order for an invention to be patent eligible, it must both be new and represent a nontrivial advancement over current scientific understanding. 35 U.S.C. $§ 103$ (2006). If an invention was obvious to the person of ordinary skill in the art or was already in the public domain, the invention would have likely arisen without the patent incentive. In contrast, an invention that represents a significant advancement in the art may not have arisen but for the patent inducement.

9. Mark A. Lemley \& Carl Shapiro, Probabilistic Patents, 19 J. ECON. PERSP. 77 (2005).

10. See generally James Bessen \& Michael J. Meurer, Patent Failure: How Judges, Bureaucrats, and Lawyers Put InNovators at Risk (2008); DAN L. Burk \& Mark A. Lemley, The PATEnt CRisis AND How the Courts CAN Solve It (2009); JAFFe \& LeRneR, supra note 5.

11. See, e.g., Fed. Trade Comm'n, To Promote Innovation: The Proper Balance of COMPETITION AND PATENT LAW AND POLICY (2003), available at http:///www.ftc.gov/os/2003/10/ innovationrpt.pdf (discussing how poor quality patents harm innovation); Mark A. Lemley, Rational Ignorance at the Patent Office, 95 Nw. U. L. REv. 1495, 1495 n.1 (2001) (citing a litany of sources critical of the PTO for issuing invalid patents); Mark A. Lemley \& Bhaven Sampat, Is the Patent Office a Rubber Stamp?, 58 EMORY L.J. 181, 185 (2008) (noting the widespread consensus that the PTO is routinely issuing invalid patents that impose costs upon the public); Doug Lichtman \& Mark A. Lemley, Rethinking Patent Law's Presumption of Validity, 60 STAN. L. REV. 45, 47 n.5 (2007) (citing a number of sources calling for reform of the patent system because the PTO is issuing a large number of undeserving patents); John R. Thomas, Collusion and Collective Action in the Patent System: A Proposal for Patent Bounties, 2001 U. ILL. L. REv. 305, 320-22 (demarcating the social costs associated with improvidently issued patents). 
concern. ${ }^{12}$ Yet our findings suggest this charge is underinclusive, as they provide evidence that the PTO is not only likely biased toward issuing patents but also that the Agency is likely biased toward issuing particular types of patents-those with a high probability of being renewed or those that are filed by large entities. Of course, eliminating the Agency's overgranting tendencies requires not only an understanding of the extent of its bias but also the mechanisms that create pressure on the Agency to issue patents. Unfortunately, up to this point, there has been a failure on both counts. ${ }^{13}$ As a result, recent patent reform efforts are unlikely to eliminate the granting pressure identified in this Article. ${ }^{14}$

From a policy perspective, our results also suggest that congressional action intended to promote innovation with respect to entrepreneurs and small firms may have the exact opposite effect. Largely in recognition that individuals and small entities both constitute a significant source of innovative activity and rely more heavily on the patent system than larger enterprises, Congress provided a $50 \%$ reduction in patent fees to these entities. ${ }^{15}$ Yet we find evidence that this reduction in patent fees has the unintended consequence of likely biasing the PTO toward granting patents associated with large enterprises. Thus, it is possible that the alleged benefits small entities obtain by paying reduced patent fees are outweighed by the harms they experience in the marketplace because the PTO is extending preferential treatment toward large entities.

On a theoretical level, our modeling of the various ways in which the PTO may distort its practices in light of its funding structure builds on, and fills various gaps in, a literature that has attributed the PTO's perceived bias toward issuing patents to a number of causes. ${ }^{16}$ To the extent scholars have posited that the PTO's

12. Lemley \& Sampat, supra note 11, at 185.

13. See infra notes $16-18$ and accompanying text.

14. See infra Part V.

15. 35 U.S.C. $\S 41(\mathrm{~h})(1)(2006)$.

16. For example, scholars have argued that the PTO is so underfunded and, hence, hamstrung from spending sufficient time examining patent applications to reject patents, see, e.g., JAFFE \& LERNER, supra note 5, at 130-33 (describing the PTO's budgetary woes); Lemley, supra note 11, at 1500 (noting that examiners spend on average only eighteen hours reviewing a patent application), that the patent examiners compensation system favors allowances, see, e.g., Thomas H. Stanton et Al., NAT'L ACAD. of Public Admin., U.S. Patent \& Trademark Office: Transforming to MeEt the Challenges of the 21St Century 102 (2005), available at http://www2.aipla.org/Content/ContentGroups/Issues_and_Advocacy/Comments2/Patent_and_Tr ademark_Office/20055/NAPAFullReport.pdf (paraphrasing one patent examiner's statement saying that the productivity schedule is "highly biased toward early allowances"); Clarisa Long, The PTO and the Market for Influence in Patent Law, 157 U. PA. L. REv. 1965, 1991 (2009) 
user-fee income may bias the Agency toward issuing patents, they have done so chiefly under the simple premise that funding the PTO through fees paid by patent applicants may lead it to make decisions that favor applicants (i.e., grant patents) at the expense of the public (i.e., apply the patentability standards in a nonbiased fashion). ${ }^{17}$ One of us has previously argued that by ignoring the structure of user fees, legal scholarship has overlooked the import that the more finegrained, structural components of agency financing may play in influencing agency decisionmaking. ${ }^{18}$ This Article builds on this previous work by exploring how various PTO objectives would interact

("Internal PTO practices create a bias in favor of granting patents."); Robert P. Merges, As Many as Six Impossible Patents Before Breakfast: Property Rights for Business Concepts and Patent System Reform, 14 BERKELEY TECH. L.J. 577, 607 (1999) ("Consequently, the only way to earn bonus points with confidence is to allow a patent application.”); Thomas, supra note 11, at 32425 (discussing the PTO's employee shortage and employee compensation structure contribute to disproportionate amounts of patent allowances), that the asymmetric review of the Agency's decisions bias it toward expanding substantive patent law, Melissa F. Wasserman, The PTO's Asymmetric Incentives: Pressure to Expand Substantive Patent Law, 72 OHIO ST. L.J. 379, 40106 (2011), and that the burden of proof is on the examiner to show that a patent should not issue, Thomas, supra note 11, at 325 ("Long-established practice places the burden of persuasion and initial burden of production upon examiners to generate rejections.”).

17. See, e.g., Stuart Minor Benjamin \& Arti K. Rai, Who's Afraid of the APA? What the Patent System Can Learn from Administrative Law, 95 GEO. L.J. 269, 314 (2007) ("[PTO] is favorably disposed to patent holders . . . [in part because] the Agency as a whole is funded by applicant fees.”); Jeanne C. Fromer, Patent Disclosure, 94 IowA L. REv. 539, 579 n.178 (2009) (“A pro-patent bias also arises because the PTO is wholly funded by patent-applicant fees."); Long, supra note 16, at 1994 ("[T] he PTO's budgetary structure . . . creates the incentive for the PTO to favor patentees (who pay fees to the PTO) over nonpatentees (who do not)."); Michael J. Meurer, Patent Examination Priorities, 51 WM. \& MARY L. REV. 675, 699 (2009) ("The PTO has endorsed a 'customer service' orientation that stresses the importance of meeting the needs of patent applicants. This orientation may be motivated in part by the dependence of the agency on fees to fund its operation.").

18. While at least two scholars have noted the current fee structure may bias the Agency to grant patents, they have not begun to explore how the PTO may have a differential bias across patent type. Compare Arti K. Rai, Growing Pains in the Administrative State: The Patent Office's Troubled Quest for Managerial Control, 157 U. PA. L. REV. 2051, 2062 (2009) ("[T] he current fee structure also sets up an obvious financial incentive for the PTO to grant patents."), and Long, supra note 16, at 1994 ("[T]he PTO's budgetary structure creates a bias in favor of granting patents and encouraging inventors to apply for patents."), with Wasserman, supra note 16, at 407-14 (asserting that the PTO's budgetary structure favors granting patents that are likely to earn the most revenue-i.e., patents directed toward technologies with high renewal rates and patents issued to large entities).

This gap in the literature is all the more puzzling in consideration of the substantial literature regarding the incentives created by various fee structures and compensation structures in other decisionmaking contexts. To provide one example, scholars in health economics, law, and policy have long acknowledged the expansionary distortions in physician decisionmaking that may follow from a "fee-for-service" payment system that more generously compensates physicians for providing their patients with a greater quantity of medical services, such as office visits, procedures, and tests. See, e.g., Thomas G. McGuire, Physician Agency, in HANDBOOK OF HEALth ECONOMics 461, 517-19 (A.J. Culyer \& J.P. Newhouse eds., 2000). 
with both the Agency's fee structure and the nuances of the PTO's budgetary process and, of course, empirically testing the hypotheses that result from this exploration.

Despite a general perception in the literature that the PTO is routinely granting bad patents, ${ }^{19}$ it is important that scholars turn to an empirical analysis of PTO decisionmaking, as we endeavor to do in this Article, in order to understand whether the PTO is, in fact, deviating from otherwise optimal practices. After all, there are at least three reasons to doubt that the Agency's funding mechanism would bias the PTO toward issuing patents. First, as administrative law scholars have long debated, the nature or objectives of high-level agency administrators are unclear. ${ }^{20}$ Do bureaucrats seek larger budgets for self-interested reasons or solely to better accomplish the Agency's mission? Second, Congress has never given the PTO the authority to spend all of the fees it collects, potentially blunting any incentives of the PTO to grant additional patents in an attempt to expand its budget. ${ }^{21}$ Third, emphasizing the autonomous nature of individual patent examiners and the difficulties involved in supervising examiners, ${ }^{22}$ the current literature has questioned the

19. See sources cited supra note 11.

20. Compare William A. Niskanen, JR., BurEaucracy AND REPREsentative GOVERNMENT 38-42 (1971) (arguing that bureaucrats seek enlarged budgets because they are positively correlated with other goods the bureaucrat values such as power, prestige, and salary), and The Budget-MAXimizing Bureaucrat: ApPraisal AND Evidence (Andre Blais \& Stephane Dion eds., 1991) (aggregating a number of essays and studies that support the assertion that bureaucrats seek enlarged budgets), with JAMES Q. WILSON, BUREAUCRACY: WHAT GOVERNMENT AgEncies Do AND Why ThEy Do IT 182 (1989) ("The view that all bureaus want larger budgets ignores the fact that there is often a tradeoff between bigger budgets on the one hand and the complexity of tasks, the number of rivals, and the multiplicity of constraints on the other."), Daryl J. Levinson, Empire-Building Government in Constitutional Law, 118 HARV. L. REV. 915 (2005) (arguing that empire-building of agencies is overstated because bureaucrats do not have the same motives as corporate leaders), and Michael A. Livermore, Cause or Cure? Cost-Benefit Analysis and Regulatory Gridlock, 17 N.Y.U. ENVTL. L.J. 107, 120 (2008) (challenging the notion that bureaucrats will always seek to increase budgets).

21. See infra notes $25-26$ and accompanying text.

22. See, e.g., Michael Abramowicz \& John F. Duffy, Ending the Patenting Monopoly, 157 U. PA. L. REV. 1541, 1544, 1551, 1559-60 (2009) (noting the PTO's difficulties in controlling patent examiner's output); Meurer, supra note 17, at 700 (detailing the difficulties associated with implementing reforms affecting patent examiners).

Several scholars have found that patent examiner characteristics have an effect on patent outcomes. See, e.g., Iain M. Cockburn et al., Are All Patent Examiners Equal? Examiners, Patent Characteristics, and Litigation Outcomes, in PATENTS In THE KNOWLEDGe BASED ECONOMY 19 (Wesley M. Cohen \& Stephen A. Merrill eds., Nat'l Acads. Press 2003) (finding that differences in examiners explain a significant percentage of the variation in the characteristics of issued patents, and that some examiners are more likely than others to have their patents upheld in court); Lemley \& Sampat, supra note 5 (finding that more experienced examiners cite less prior art and are more likely to grant patents); Douglas Lichtman, Rethinking Prosecution History 
ability of the PTO to enact top-down directives, such as pressure to grant more patents (especially in targeted areas). ${ }^{23}$

Finally, our findings also shed light on some of the abovementioned ambiguities surrounding agency responsiveness to financial incentives. Our results contradict the idea that bureaucrats seek to maximize their budgets for self-interested reasons-i.e., in an effort to increase their own salaries, prestige, or advancement. Instead, our findings suggest that, to the extent bureaucrats seek enlarged budgets, they do so as a result of being mission minded but resource constrained.

The rest of the Article is organized as follows. Part I delineates the PTO's possible financial incentives to grant patents and begins to explore the extent to which the PTO will act on this incentive by introducing two competing models of agency behavior: the selfinterested PTO and the benevolent PTO. Part II further refines these models of agency behavior by examining how the PTO's financial incentives likely vary across patent types. Part II also introduces the predictions of these models, which serve as the hypotheses that will guide our empirical analysis. Part III describes the data set and methodology utilized. The results of our empirical analysis are presented in Part IV. Part V begins to explore the implications of our results and also assesses potential methods to reduce the PTO's financial tendency toward issuing patents. This Part also concludes that the recently enacted America Invents Act, which grants the PTO fee-setting authority, is unlikely to extinguish the PTO's financial predisposition to grant patents.

\section{THE PTO’S FINANCIAL INCENTIVES AND ITS OBJECTIVES}

This section describes how the PTO's current budgetary process, including its fee schedule, sets up possible financial incentives to grant patents. ${ }^{24}$ It next turns to examining when and if the PTO is likely to act on those financial incentives by exploring two competing models of agency behavior: the self-interested PTO who desires to maximize its budget and the benevolent-but-resource-constrained PTO

Estoppel, 71 U. CHI. L. REV. 151 (2004) (finding that certain examiners more systematically required applicants to narrow the scope of their patents).

23. See, e.g., Abramowicz \& Duffy, supra note 22, at 1559-60, 1563-64 (discussing the difficulty the PTO has controlling examiner conduct despite strict rules and oversight).

24. We use the term patents in this Article to refer to "utility" patents. A utility patent protects the way an article is used and works. See 35 U.S.C. $§ 101$ (2006). 
who seeks additional funding in order to match its revenue with its expenses.

\section{A. The PTO's Budget Process and Its Possible Financial Incentives to Grant Patents}

Historically, the PTO has been funded largely by taxpayer revenues. In 1991, the Agency was made to essentially fund its entire operations through user fees. ${ }^{25}$ The PTO, however, was not given feesetting authority-Congress chose to remain the sole arbitrator of patent fee levels. ${ }^{26}$ Importantly, Congress also did not give the Agency the right to automatically spend its fee collections; instead the PTO must receive congressional approval through annual appropriations to utilize its fee revenue. ${ }^{27}$

Prior to 2004, Congress routinely set the Agency's budget to a level that was essentially below both its estimated and actual fee collections. $^{28}$ Since 2004, the Agency's spending authority has been

25. Omnibus Budget Reconciliation Act of 1990, Pub. L. No. 101-508, § 10101, 104 Stat. 1388. The PTO's budget in 1991 was over three hundred and seventy million dollars, of which three million were from general revenue funds. U.S. PATENT \& TRADEMARK OfFICE, 1991 ANNUAL REPORT 1-2 (1991) [hereinafter 1991 ANNUAL REPORT].

26. The PTO only recently obtained fee-setting authority. Leahy-Smith America Invents Act, Pub. L. No. 112-29, § 10(a), 125 Stat. 284, 316 (2011) (codified at 35 U.S.C.A. § 41 (West 2012)). Prior to 2011, the PTO lacked fee-setting authority and any significant change in the filing fees, issuance fees, and maintenance fees required congressional action. See 35 U.S.C. $\S$ 41(d) (2006) (amended 2011) (limiting the PTO's discretion in setting fees to minor issues such as "processing, services, or materials").

27. The PTO is funded through discretionary spending, which means that Congress evaluates the Agency and its funding needs annually during the appropriations cycle. See Elizabeth Garrett, Rethinking the Structures of Decisionmaking in the Federal Budget Process, 35 HARV. J. ON LEGIS. 387, 398-400 (1998) (describing discretionary spending and the budget process generally).

28. In 1991, when Congress made the Agency essentially user-fee funded it concomitantly enacted a $69 \%$ surcharge on certain patent fees. Omnibus Budget Reconciliation Act of 1990, Pub. L. No. 101-508, § 10101(a), 104 Stat. 1388. From the fiscal years of 1991 to 1998, fees collected from users were fully available to the PTO; however, surcharge revenue was not. Starting in the fiscal year of 1992, Congress limited the Agency's ability to spend surcharge fees, using the fees to fund other government programs. See Consolidated Appropriations Act, 2004, Pub. L. No. 108-199, div. B, tit. II, 118 Stat. 3.

In 1999 the surcharge fees expired. From 1999 to 2003, Congress made a certain dollar amount of fees unavailable for PTO use each year and then, in differing amounts over the years, allowed the Agency to use some, but not all, of the prior year's fees. The result, however, was that for the fiscal years of 1999 to 2003, the Agency's budget was essentially set below its estimated fee collections. U.S. PATENT \& Trademark OfFICE, PERFormance AND ACCOUntability REPORT: Fiscal YeAR 2003, at 54 (2003) [hereinafter 2003 PERFoRMANCE AND ACCOUNTABILITY REPORT], available at http://www.uspto.gov/about/stratplan/ar/2003/2003 annualreport.pdf; U.S. PATENT \& TRADEMARK OfFICE, PERFormance AND ACCOUNTABility REPORT FOR FISCAL YEAR 2002, at 54 (2002) [hereinafter 2002 PERFORMANCE AND 
capped at its projected revenue stream, which has resulted in the PTO's budget being larger than its fee collections at times. ${ }^{29}$ When the PTO's fee collections fall below its appropriated budget, the Agency will experience a budgetary shortfall, as Congress does not provide the Agency with the difference. ${ }^{30}$ In contrast, if the PTO's fee collections surpass its spending authority, the excess fees are not immediately available to the PTO. ${ }^{31}$ On occasion, the PTO has obtained

ACCOUNTABILITY REPORT], available at http://www.uspto.gov/web/offices/com/annual/2002/158.pdf; U.S. PATENT \& TRADEMARK OfFice, PeRformance AND ACCOUnTABility Report Fiscal YEAR 2001, at 58 (2001), available at http://www.uspto.gov/web/offices/com/annual/2001/ 01performreport.pdf; U.S. Patent \& TRAdEMark OfFice, Performance and ACCOUnTability REPORT, FISCAL YEAR 2000, at 49 (2000), available at http://www.uspto.gov/about/ stratplan/ar/2000/00findisc.pdf; U.S. PATENT \& TRADEMARK OfFICE, A PATENT AND TRADEMARK OfFICE REVIEW: CENTURY OF AMERICAN InVENTION, FisCAL YEAR 1999, at 28 (1999), available at http://www.uspto.gov/about/stratplan/ar/1999/99mssgchief.pdf. For example, in the fiscal year of 2002 the PTO estimated its fee collections would total $\$ 1,346$ million. OfFICE OF MGMT. AND Budget, Budget of the U.S. Government Fiscal Year 2002, Appendix, Department of COMMERCE 227 (2002), available at http://www.gpo.gov/fdsys/pkg/BUDGET-2002-APP/pdf /BUDGET-2002-APP-1-6.pdf. That year, Congress chose to set the office's budgetary resources for spending to $\$ 1,146.7$ million, of which $\$ 282.3$ million was from fees collected in fiscal years 2000 and 2001. Congress also appropriated $\$ 843.7$ million from fees collected during fiscal year 2002; however, $\$ 304.1$ million from fees collected during fiscal year 2002 was not available for spending. 2002 PERFORMANCE AND ACCOUNTABILITY REPORT, supra, at 54.

29. U.S. Patent \& Trademark Office, Performance and Accountability Report For FISCAL YEAR 2004, at 60 (2004) [hereinafter 2004 PERFORMANCE AND ACCOUNTABILITY REPORT], available at http://www.uspto.gov/about/stratplan/ar/2004/2004annualreport.pdf; U.S. PATENT \& Trademark OfFICE, PERFormance AND ACCOUNTABILITy REPORT FOR FisCAL YeAr 2005, at 80 (2005) [hereinafter 2005 PERFORMANCE AND ACCOUNTABILITY REPORT], available at http://www.uspto.gov/about/stratplan/ar/2005/2005annualreport.pdf; U.S. PATENT \& TRADEMARK OfFice, PERFormance AND ACCOUNTABILITY REPORT FisCAL YeAR 2006, at 83 (2006) [hereinafter 2006 PERFORMANCE AND ACCOUNTABILITY REPORT], available at http://www.uspto .gov/about/stratplan/ar/2006/2006annualreport.pdf; U.S. PATENT \& TRADEMARK OfFICE, PERformance AND ACCOUNTABILITy RePORT Fiscal YeAR 2007, at 53 (2007) [hereinafter 2007 PERFORMANCE AND ACCOUNTABILITY REPORT], available at http://www.uspto.gov/about/stratplan/ ar/2007/2007annualreport.pdf.

30. This occurred in the fiscal years of 2005, 2006, 2008, and 2009. 2005 PERFormance AND ACCOUNTABILITY REPORT, supra note 29, at 80 (PTO was appropriated up to $\$ 1.554$ million but only collected $\$ 1.497$ million in fees); 2006 PERFORMANCE AND ACCOUNTABILITY REPORT, supra note 29 , at 83 (PTO was appropriated up to $\$ 1.683$ million but only collected $\$ 1.554$ million in fees); U.S. PATENT \& TRADEMARK OfFice, PERFormance AND ACCOUNTABILITY Report Fiscal YEAR 2008, at 54 (2008), available at http://www.uspto.gov/about/stratplan/ar/2008/ 2008annualreport.pdf (PTO was appropriated up to $\$ 1.915$ million but only collected $\$ 1.879$ million in fees); U.S. Patent \& Trademark OfFice, Performance and Accountability REPORT FISCAL YEAR 2009, at 47 (2009) [hereinafter 2009 PERFORMANCE AND ACCOUNTABILITY REPORT], available at http://www.uspto.gov/about/stratplan/ar/2009/2009annualreport.pdf (PTO was appropriated up to $\$ 2.010$ million but only collected $\$ 1.874$ million in fees).

31. This occurred in the fiscal years of 1992-2004, 2007, 2010, and 2011. 2003 PERFormance AND ACCOUNTABILITy REPORT, supra note 28, at 47 (stating that PTO fee collections exceeded spending authority); 2004 PERFORMANCE AND ACCOUNTABILITY REPORT, supra note 29, at 80; 2007 PERFORMANCE AND ACCOUNTABILITY REPORT, supra note 29, at 53; 2010 PeRformance AND ACCOUnTABility RePort, supra note 2, at 99; U.S. PAtent \& 
supplemental appropriations from Congress enabling the Agency to use all or a portion of these excess fees. ${ }^{32}$ More typically, the excess fees are utilized by Congress to fund other government operations. ${ }^{33}$ This practice, known as fee diversion, first occurred in 1992 and appears to have peaked in the late $1990 \mathrm{~s}$ to the early $2000 \mathrm{~s} .{ }^{34} \mathrm{We}$ revisit the nuances of this quasi-appropriations process when discussing the incentives posed by the practice of fee diversion in Part IV below. To illustrate the incentives posed by the Agency's fee structure, however, we proceed by simply viewing the PTO as operating off of the user fees that it collects.

Since the PTO became essentially fully user-fee funded, roughly $85 \%$ of its patent operating budget is garnered through three types of fees: (1) filing, search, and examination fees (collectively referred to as examination fees), (2) issuance fees, and (3) maintenance or renewal fees. ${ }^{35}$ Examination fees are paid at the time the application is filed, issuance fees are paid at the time a patent

Trademark Office, Performance AND Accountability Report Fiscal Year 2011, at 67 (2011) [hereinafter 2011 PERFORMANCE AND ACCOUNTABILITY REPORT], available at http://www.uspto.gov/about/stratplan/ar/2011/USPTOFY2011PAR.pdf.

32. See, e.g., United States Patent and Trademark Office Supplemental Appropriations Act, 2010, Pub. L. No. 111-224, 124 Stat. 2385 (designating a supplemental appropriation in the fiscal year of 2010 enabling the PTO to spend an additional $\$ 129$ million in fee collections, bringing the PTO's spending authority up to $\$ 2.016$ billion in fee collections).

33. In theory these surplus fees may become available to the Agency in future years-the PTO still has these fees on its books as "temporarily unavailable." See, e.g., 2011 PERFORMANCE AND ACCOUNTABILITY REPORT, supra note 31, at 67 . However, it is widely believed that the PTO is unlikely to ever receive the authority to spend these fees, at least not any significant portion of them. Intellectual Prop. Owners Ass'n, Understanding Patent Fee Diversion and How It Is Affected By CurRent Senate And House Patent Reform Bills 1 (2011), available at http://www.ipo.org/AM/Template.cfm?Section=Home\&ContentID=30761\&Template=/CM/Conten tDisplay.cfm ("No one expects that these fees will ever be made available to the USPTO.").

34. Intellectual Prop. Owners Ass'n, User Fees Diverted from the U.S. Patent and Trademark Office (USPTO) 1991-2005, INTELL. PROP. OWNERS ASS'N, http://www.ipo.org/ AM/Template.cfm?Section=Search\&section=USPTO_Fees_and_Funding\&template=/CM/Content Display.cfm\&ContentFileID=2294 (last modified Dec. 16, 2004). Importantly, the America Invents Act does not conclusively end the practice of fee diversion, although it arguably diminishes the chances it will occur. See Pub. L. No. 112-29, § 22, 125 Stat. 284, 336 (2011). The America Invents Act creates a new account, known as the "reserve fund," wherein fees the PTO collects above its appropriated budget are deposited, but does not guarantee the PTO access to these fees. $I d$. The language of the Act defers to future appropriations bills as to this matter; therefore, it appears to leave open the possibility that fee diversion may occur in the future. See $i d$.

35. 2010 PERFORMANCE AND ACCOUNTABILITY REPORT, supra note 2, at 55 (stating that approximately $84 \%$ of total patent income comes from maintenance fees, fees related to initial application for filing, search, and examination, and issue fees); U.S. PAT. \& TRADEMARK OfFICE, A Patent and Trademark Office Review: Working For OuR Customers, Fiscal Year 1994, at 59 (1995) [hereinafter 1994 ANNUAL REPORT] (stating that approximately 83\% of total patent income comes from maintenance fees, filing fees, and issue fees). 
application is granted, and maintenance fees are paid periodically over the lifetime of an issued patent so that the patent can remain enforceable.

While examination fees account for approximately $30 \%$ of the PTO budget, these fees fail to cover the actual cost incurred by the PTO to examine applications. ${ }^{36}$ Consider, for example, that in the fiscal year of 2011 the PTO estimated that the average cost of examining a patent application was approximately $\$ 3,600 .{ }^{37}$ Yet, during the fiscal year of 2011 the examination fee was set at $\$ 1,090$ for large for-profit corporations and half that amount for individuals, small firms, nonprofit corporations, or other enterprises that qualify for "small entity" status. ${ }^{38}$ Therefore, the level of examination fees covered less than one-third of the actual examination costs for large corporations and less than one-sixth of actual costs for small entities.

The PTO is heavily dependent on issuance fees and maintenance fees, which account for over 50\% of the PTO's patent budget, to fund its operations. ${ }^{39}$ These post-allowance fees are typically larger than the examination fees. In the fiscal year of 2011 , the issuance fee was set at $\$ 1,510$, and the maintenance fees that are due at three-and-a-half, seven-and-a-half, and eleven-and-a-half years from the date the patent issues were $\$ 980, \$ 2,480$, and $\$ 4,110$, respectively. ${ }^{40}$ Again, small entities pay half these amounts. The result is that the vast majority of the PTO's budget is gained through fees that the Agency collects only if a patent is granted. Further, the majority of the Agency's operational costs are incurred by processing patents; ${ }^{41}$ the expenses associated with issuing and maintaining a patent are minimal. ${ }^{42}$ Thus, these post-allowance fees are almost

36. 2009 PERFoRMANCE AND ACCOUNTABILITy REPORT, supra note 30, at 49 (stating $31.3 \%$ of total patent income comes from filing, search, and examination fees).

37. 2011 PERFORMANCE AND ACCOUNTABILITY REPORT, supra note 31, at 17 (stating that in 2011 the average patent cost $\$ 3,594$ to examine).

38. See 37 C.F.R. $\S 1.16(a)(1)$ (2011) (listing a basic filing fee of $\$ 330$ and $\$ 165$ for a small entity); 37 C.F.R. $\S 1.16(\mathrm{k})$ (listing a utility search fee of $\$ 540$ and $\$ 270$ for a small entity); 37 C.F.R. $\S 1.16(\mathrm{o})$ (listing a utility examination fee of $\$ 220$ and $\$ 110$ for a small entity). Entities defined by the PTO as "small" include individuals, nonprofit corporations, or corporations that qualify as small businesses under the Small Business Act. 37 C.F.R. § 1.27(a)(1)-(3).

39. See 2010 PERFORMANCE AND ACCOUNTABILITY REPORT, supra note 2, at 56 (noting that "renewals [fees] recoup costs incurred during the initial patent process").

40. 37 C.F.R. $§ 1.18(a)$ (utility fee); $\S ~ 1.20(e)-(g)$ (maintenance fees).

41. 1991 ANNUAL REPORT, supra note 25, at 3 fig.1 (noting that patent processing constituted $51 \%$ of the PTO's total obligations).

42. U.S. Gov't Accountability Office, GAO-97-113, Fees ARe Not Always Commensurate With the Costs OF Services 26 (1997) (noting that "only 8.6 percent of the 
exclusively used to fund other Agency activity. The back-end fee structure and the inadequacies of the examination fees both provide a possible incentive for the PTO to grant rather than deny patents. The extent to which the PTO would act on either of these inducements depends, in part, on the objectives of the Agency and its needs.

\section{B. The PTO's Objectives}

The decisions of agencies, like those of many other entities, are influenced by a variety of factors. The purpose of this Section is not to elucidate every factor that may affect agency decisionmaking but instead to establish that under certain situations monetary concerns are likely to influence the decisionmaking process of the PTO. To this effect, this Section outlines two competing models of agency behavior. The first model assumes a self-interested bureaucrat who desires to maximize the Agency's budget. For this bureaucrat, the existence of post-allowance fees will bias the PTO toward allowing patents. The second model supposes a benevolent bureaucrat that is resource constrained. Unlike the self-interested bureaucrat, the benevolent bureaucrat's bias toward granting patents may stem solely from the PTO's examination fees failing to cover the Agency's examination expenses. However, even if examination fees were adequate, a benevolent bureaucrat may apply the patentability standards in a patent-protective direction if the Agency's overall fee collections failed to cover its operational expenses.

\section{Self-Interested Bureaucrat}

To begin, we envision a state of the world in which the PTO resembles the imperialistic maximizing bureaucrat theorized by William Niskanen. ${ }^{43}$ Niskanen posits that bureaucrats seek to maximize agency budgets because budgets are positively correlated with other goods that a bureaucrat values, such as compensation, prestige, power, and prospects for advancement. ${ }^{44}$ In other words, Niskanen contemplates a self-interested bureaucrat that puts his own

costs associated with an individual patent were attributable to the actual issue of the patent and 0.1 percent were attributable to its maintenance").

43. See generally Andre Blais \& Stephane Dion, Introduction to THE BudGET-MAXIMIZING BurEAUCRAT: APPRAISAl AND Evidence, supra note 20, at 3-11; William A. NisKanen, JR., BUREAUCRACY AND REPRESENTATIVE GOVERNMENT 38 (1971).

44. Robert A. Young, Budget Size and Bureaucratic Careers, in The Budget-MaXimizing BurEAUCRAT: APPRAISAL AND EVIDENCE, supra note 20, at 33 (citing NiSKANEN, supra note 43, at 38 ). 
interests above those of the public. ${ }^{45}$ Under Niskanen's view, it is the existence of informational asymmetries that enables high-level administrators to extract ever-increasing budgets from Congress. ${ }^{46}$

The universal nature of the maximizing bureaucrat, however, has been questioned. ${ }^{47}$ One line of challenge focuses on the extent to which high-level administrators actually profit from enlarged budgets. Even if bureaucrats were primarily self-interested there is little empirical evidence that high-level administrators accrue larger salaries when a bureau's budget grows. ${ }^{48}$ Of course, there is still the possibility that such administrators seek larger budgets for intangible benefits such as power and prestige. ${ }^{49}$ However, to date, there is little empirical evidence that supports or refutes this latter hypothesis. ${ }^{50}$ Another line of inquiry has challenged Niskanen's view that Congress is easily duped into providing agencies with inflated budgets. ${ }^{51} \mathrm{By}$ delineating the multitude of ways in which the legislature and the executive exert considerable influence over administrative agencies, scholars have largely refuted Niskanen's assumption that Congress is

45. NISKANEN, supra note 43 , at 38 .

46. Id. at $36-42$.

47. See WILSON, supra note 20, at 182 ("The view that all bureaus want larger budgets ignores the fact that there is often a tradeoff between bigger budgets on the one hand and the complexity of tasks, the number of rivals, and the multiplicity of constraints on the other."); Levinson, supra note 20, at 916 (arguing that empire-building of agencies is overstated because bureaucrats do not have the same motives as corporate leaders).

48. See Levinson, supra note 20, at 932 ("[T] he relationship between a larger agency budget and higher salaries or cushier working conditions is empirically tenuous"); Young, supra note 44, at 37-43 (concluding that studies on the relationship between budget growth and financial benefits to bureaucrats "are unanimous in offering little support, even to the weak proposition that bureaucrats become relatively better-off when the budget of their bureau grows disproportionately"). Research shows that it is seniority, not the size of the Agency budgets, that explains a substantial portion of salary increases. Ronald N. Johnson \& Gary D. Libecap, Agency Growth, Salaries and the Protected Bureaucrat, 27 ECON. INQUIRY 431-51 (1989).

49. Andre Blais \& Stephane Dion, Conclusion: Are Bureaucrats Budget Maximizers?, in The Budget-MAXIMIZING BuREAUCRAT: APPRAISAL AND EVIDENCE, supra note 20, at 357.

50. Id.

51. See Mathew D. McCubbins et al., Administrative Procedures as Instruments of Political Control, 3 J.L. ECON. \& ORG. 243 (1987); Mathew D. McCubbins et al., Structure and Process, Politics and Policy: Administrative Arrangements and the Political Control of Agencies, 75 VA. L. REV. 431, 443 (1989) (describing the appropriations process as a "low cost route" politicians use to prevent agency deviations from congressional goals); Mathew D. McCubbins \& Thomas Schwartz, Congressional Oversight Overlook: Police Patrols Versus Fire Alarms, 28 AM. J. PoL. SCI. 165, 170 (1984) (noting that "subcommittees controlling authorizations and appropriations may be in a better position to do oversight than so-called oversight committees"); $c f$. Barry R. Weingast \& Mark J. Moran, Bureaucratic Discretion or Congressional Control? Regulatory Policymaking by the Federal Trade Commission, 91 J. POL. ECON. 765, 789 (1983) (finding congressional preferences over agency action to be a statistically significant factor). 
submissive in setting agencies' budgets. ${ }^{52}$ Of course, Niskanen's views may continue to hold some relevance in that it remains possible, even likely, that both Congress and bureaucrats play influential roles in the budgetary process. ${ }^{53}$ Accordingly, we consider the manner in which a self-interested PTO of the Niskanen variety would seek to expand its budget.

While the PTO's budgetary process provides the Agency with multiple pathways to satisfy its maximizing proclivities, ${ }^{54}$ arguably the easiest way for the Agency to increase its budget is to grant more patents. In this scenario, the PTO exploits its informational monopoly on the socially optimal grant rate to artificially inflate its fee collections (and hence the budget that it requests reflecting those inflated fee collections). At the extreme, a self-interested PTO would grant every patent, as the existence of back-end fees means the Agency can maximize its fee collections by maximizing its patent grants (this is true whether or not the Agency's examination fees covered the full operational expenses of the PTO). However, there are a number of reasons why the Agency would not adopt such an excessive practice, including the fact that Congress is unlikely to believe that a $100 \%$ grant rate is optimal. Nonetheless, a selfinterested PTO can still increase its budget by biasing the Agency toward granting patents, as long as its distortionary bias remains under the threshold of congressional detection.

52. Id.

53. There is empirical evidence that suggests bureaucrats have a substantial impact on budgetary outcomes and that this impact usually results in larger budgets. Jean-Michel Cousineau \& Anne-Marie Girard, Public Sector Unions, Government Expenditures, and the Bureaucratic Model, in The BUdGET-MAXIMIZING BUREAUCRAT: APPRAISAL AND EVIDENCE, supra note 20, at 259 (finding that the presence of a public sector union in a municipality tends to increase government expenditures by about six percent).

54. Of course, the PTO could seek to increase its budget by lobbying Congress for fee increases. In this scenario, the PTO could leverage its informational monopoly on the true cost of examining patent applications to extract temporary or long-term fee increases from Congress. Because the Agency's budget is generally set to its estimated fee collections, any increase in fee levels will automatically translate into a larger budget. Niskanen's model predicts that the PTO would repeatedly and routinely ask for needless fee increases. The Agency has enjoyed some success in lobbying for larger fees, but its success has been far from universal. See infra note 57.

The Agency could also lobby for enhanced fee-setting authority. To the extent that the PTO could control its fee levels, the PTO could increase its fees in an effort to enlarge its own budget. Arguably, biasing the Agency toward granting patents is the easiest pathway to increase the PTO's budget, as this requires the least congressional action. 


\section{Benevolent-but-Resource-Constrained Bureaucrat}

The PTO bureaucrat, however, does not need to be selfinterested in order to seek a larger budget. High-level administrators may also seek more abundant budgets because of their values; there is ample evidence that many civil servants are mission minded. ${ }^{55}$ The "benevolent bureaucrat" is a high-level administrator who attempts to increase agency funding solely for the purpose of allowing the agency to better accomplish its mission.

While the benevolent PTO's preferred method of augmenting the Agency's budget is to lobby Congress for increased fee levels, ${ }^{56}$ this approach is unlikely to yield routine success. ${ }^{57}$ Thus, in certain situations even an administrator that is only attempting to better accomplish the PTO's mission may bias the Agency toward issuing patents in an effort to augment the Agency's budget.

Congress has stipulated that the PTO funds its entire operations through fee revenue. ${ }^{58}$ Yet, at the same time, Congress set the Agency's fee structure so that examination fees fail to cover twothirds of the Agency's costs to examine patent applications. The inadequacy of the examination fees necessitates the Agency's dependence on post-allowance fees to subsidize the examination process. More generally, the fact that half of the Agency's budget

55. See Kenneth A. Shepsle \& Mark S. BoncheK, Analyzing Politics: Rationality, BEhavior, AND Institutions 347-48 (1997); Laurence E. Lynn, Jr., The Budget-Maximizing Bureaucrat: Is There a Case?, in THE Budget-MAXIMIZING BurEAUCRAT: APPRAISAls AND EVIDENCE, supra note 20, at 66 (discussing case studies that indicate many civil servants are mission minded).

56. This course of action would allow the PTO to increase its budget without distorting its own granting behavior.

57. While there is general agreement that the PTO's present budget is insufficient for the Agency to carry out its expected responsibilities, FED. Trade COMM'N, TO PROMOTE InNovation: The Proper Balance of Competition And Patent Law And Policy 10 (2003) ("Hearings participants unanimously held the view that the PTO does not receive sufficient funding for its responsibilities."), Congress has on a number of occasions refused to increase fee levels. Fee changes appear to be harder to enact when they are not supported by patent applicants. For example, a 1990 and 1991 campaign to end small-entity status and a 2002 campaign to increase fee levels and restructure fees were largely unsuccessful because patent applicants did not support these increases. See Traci Watson, Patent Office Drops Plan to Raise Fees, 356 Nature 645, 645 (1992) (noting that after "failing twice to convince Congress that small-scale inventors do not deserve a price break, the US Patent and Trademark Office (PTO) has dropped its opposition to such a discount" and that "small inventors convinced Congress that a higher maintenance fees [sic] would weaken the US economy").

58. It was congressional intent that the fees the Agency collects cover the full operating needs of the Agency. See WENDY H. SCHACHT, Cong. RESEARCH SERV., RS20906, U.S. PATENT AND Trademark Office ApPropriations Process: A Brief Explanation 1 (2011) (reviewing the Patent and Trademark Office's funding as a result of the Omnibus Reconciliation Act). 
stems from these back-end fees suggests the PTO is heavily dependent on these fees to cover its operational expenses. Accordingly, the PTO must grant patents at a sufficiently high rate to recoup these costs.

It is of course possible that the Agency's nonbiased grant ratei.e., the rate at which it would grant patents if it were solely applying the patentability standards in a nonbiased fashion-is at a rate such that the PTO would indeed be able to cover its operational costs. In this instance, a benevolent PTO would not be bound by any resource constraints and would thus feel no need to distort its granting practices in an effort to generate additional fees. However, if this otherwise nonbiased grant rate is such that its current stream of fee collections based on these granting patterns is insufficient to cover the Agency's operational expenses-i.e., the Agency's grant rate is below a sustainability threshold rate-then the Agency will need to raise additional revenues in order to achieve financial sustainability. In this instance, the PTO may find itself inclined to increase its granting tendencies in order to cover this shortfall.

A number of time-varying factors may disrupt the equilibrium reached between the Agency's back-end fees and front-end and other operational costs and thus induce a bias toward granting. The PTO is more likely to trigger its sustainability constraint and encounter an imbalance between its back-end fees and examination or other operational costs under two broad scenarios: (1) when its nonbiased grant rate drops below the threshold rate required to break even, taking as given all of those factors that shape the break-even threshold (discussed below) or (2) when that threshold rate itself rises, taking as given the PTO's nonbiased rate of granting. This first scenario may arise if the quality of the stream of incoming patents deteriorates, leaving the PTO otherwise inclined to grant less frequently. The second scenario (i.e., an increase in the threshold sustainability rate) may materialize upon the occurrence, among others, of the following developments: (1) patentees elect to pay their maintenance fees at a lower rate, (2) aggregate examination costs rise due to a shift in patent applications toward more complex technology classes (to which the PTO allocates more examination hours), (3) the aggregate incidence of small-entity applicants rises, and (4) patent examinations demanded of the PTO increase (relative to the existing stock of patents from which the PTO may collect post-allowance fees). ${ }^{59}$ In each such instance, the indicated development will decrease

59. The PTO is dependent on renewal fees from patents that were issued three-and-a-half, seven-and-a-half, and eleven-and-a-half years ago to sustain its processing of patent applications 
the ratio between the back-end fees to be collected by the PTO and the obligatory operational costs of the PTO and thus, all else equal, increase the rate at which the Agency must grant patents so that its fees will be able to cover the Agency's expenses.

In the event that any of the above developments do indeed challenge the ability of the Agency to finance its operational costs through the fees generated by its nonbiased patent grants, the benevolent PTO may find that it is left with no other choice than to increase its grant rate in order to break even. ${ }^{60}$

\section{THE DifFERENTIAL IMPACT OF THE AGENCY's FinANCIAL INCENTIVES}

The previous Part established that the PTO can increase its fee collections and hence likely its budget by granting additional patents, and, in order to better understand when high-level administrators would bias the PTO toward granting patents, introduced two different models of agency behavior: the self-interested bureaucrat who desires to maximize the Agency's budget and a resource-constrained, benevolent bureaucrat who desires to generate additional funds in order to maintain financial sustainability. This Part further refines these models by considering an additional nuance in Agency decisionmaking: the PTO's monetary incentives likely vary across patent types. Although the Agency's basic fee structure preferences patent grants over denials, not all patents grants generate equal revenue. ${ }^{61}$ As a result, the PTO may find that it will best achieve the goals of self-interest or benevolence by granting more patents of certain types relative to others. This Article examines two

today. However, the PTO is processing many more applications today than it was even four, eight, or twelve years ago. As the ratio of the PTO's fee levels has not dramatically changed over time, it is unlikely that the fee levels were set to allow for such a dramatic growth in the volume of processed patent applications. Thus, the PTO's financial sustainability may be threatened solely by the fact that the Agency, which is under continued pressure to expand its capacity to examine patent applications in order to decrease its growing backlog, must fund its expansion in processing capacity based on previously issued patents.

60. David S. Kim \& Glenn M. Kubota, Behind the Scenes at the USPTO: Accounting for the Supervisory Patent Examiner, MorRISON \& Foerster Q. News, Summer 2011, at 2, 3 ("One former examiner recalled that allowances were being encouraged at the same time that USPTO fee revenues were reported as being low.”). In an effort to reestablish financial equilibrium, the PTO could attempt to cut costs, such as enacting a hiring freeze. However, any such efforts would only leave the PTO less able to process the substantial (and likely growing) number of examinations demanded of the Agency to which the Agency is obligated to respond.

61. See Wasserman, supra note 16, at 412-14 \& n.129 (noting that the PTO stands to earn more money by granting patents in technologies with high renewal rates and patents associated with large entities). 
characteristics that bear on the PTO's ability to earn increased revenue by issuing additional patents of certain types: (1) the rate of renewal or maintenance among patents of certain types and (2) the entity size (large vs. small) of the relevant patent applicant. ${ }^{62}$

The latter characteristic, entity size, is immediately discernible to the PTO upon the filing of a patent application. Patent examiners, who are charged with reviewing applications and making a decision on the patentability of the invention, know the entity size of the patent applicant. ${ }^{63}$ Because small entities pay half the examination, issue, and maintenance fees of large entities, entity size has a significant impact on the magnitude of the Agency's fee stream. In contrast, maintenance rates are not readily apparent to the Agency upon the filing of a patent application. However, the PTO may assess the likelihood that a given patent will ultimately pay renewal fees by using relevant historical data on maintenance rates associated with patents within the same technology category of the application. The PTO may assign these categorical likelihoods using a relatively coarse classification of technology types (e.g., chemical applications, electrical device applications, etc.) or, perhaps, using the more fine-grained, internal classification system that the PTO uses to instruct its examination search process. ${ }^{64}$ Finally, it should be noted that unlike entity size, patent class and technology types do not cause the maintenance fees paid by patent applicants to vary.

While this study is not designed to explore the mechanism by which additional patents are granted, we believe there are at least two

62. See id. at $412 \mathrm{n} .129$ (noting that because small entities pay half the amount of issue and renewal fees as large entities, the PTO stands to make twice as much fee revenue by granting a patent to a large relative to a small entity); $i d$. at 412-14 (noting that because patentees in certain technological sectors are more likely to renew their patents than other technological sectors, the PTO stands to earn more fee revenue by granting a patent associated with a technology that has a high renewal rate relative to a patent associated with a technology that has a low renewal rate).

63. This information is included in the patent application documents provided to patent examiners. Patent applications are not sorted by large and small entities. Applications for the most part are randomly assigned to patent examiners that have the technological expertise to examine the application. See Lemley \& Sampat, supra note 5, at 818.

64. Every patent application that is filed with the PTO is assigned a classification before it enters examination. The Agency utilizes classifications to funnel patent applications to examiners with the prerequisite scientific knowledge to review the application. With respect to the examination complexity factor, the PTO is well suited to differentiate across patent applicants using this fine-grained internal classification system (as opposed to a broader technological classification), given that the complexity measures used to allocate examination hours (and thus examiner pay) are determined in the first instance with reference to the applicant's patent class. 
different channels for favoring certain patent types. ${ }^{65}$ The first is a top-down channel, wherein senior-level officials who are responsive to the post-allowance fee differential instruct examiners to preferentially grant patents filed by large entities and high renewal-rate technologies relative to others. The PTO's ability to extend such categorical or technology-specific instructions to examiners is facilitated by the Agency's organizational structure, which is itself largely based on technological divisions. ${ }^{66}$ The second is an examinerfocused channel, whereby patent examiners themselves, without prompting from supervisors, respond to the profitability implications of varying renewal rates and entity size.67 Patent examiners, especially senior examiners, may internalize the negative impact of budgetary shortfalls to the Agency. ${ }^{68}$ Thus, patent examiners may possess sufficient motivation by themselves to preferentially grant patents filed by large entities and high renewal-rate technologies relative to others when the PTO's fee collections are low.

The rest of this Part proceeds by considering the manner in which each of the two above-mentioned characteristics (i.e., renewal rates and entity size) bears on the profitability of the PTO's marginal

65. In future work we plan to explore this mechanism in more depth.

66. Once a patent application has been assigned a technology classification, it is then, based on its class number, routed to an Art Unit, where it eventually will be examined by a patent examiner. Lemley \& Sampat, supra note 5, at 818. Art Units may be assigned patent applications from one class, a portion of a class, or from several classes involving closely related technology. See Patent Classification: Classes Arranged by Art Unit, U.S. Pat. \& Trademark OFFICE, http://www.uspto.gov/patents/resources/classification/art/index.jsp (last modified Oct. 3, 2012). Art Units are likewise aggregated into larger parcels that contain anywhere from five to fifteen Art Units and are eventually aggregated into one of nine technology centers. Patent Technology Centers, U.S. PAT. \& TRADEMARK OFFICE, http://www.uspto.gov/about/contacts/ phone_directory/pat_tech/index.jsp (last modified Feb. 17, 2010) (listing the nine patent technology centers within the U.S. Patent and Trademark Office). This hierarchical structure creates a situation in which patents of a particular PTO class are consistently examined by a targeted population of examiners (i.e., applications within a particular class are not randomly assigned among a large number of Art Units; rather, they are assigned to one or a few Art Units). This consistency makes it easier for top-level officials within the Agency to coordinate with and direct examiners to grant more patents in one technology category (for example, one with a higher renewal rate) relative to another category (for example, one with a lower renewal rate).

67. Patent examiners may be consciously or subconsciously responding to profit variations of patents.

68. Alternatively, patent examiners may be responding to low fee collections by favoring certain types of patents over others because they recognize the negative impact of budgetary shortfalls to their daily life (e.g., an elimination of overtime). Examiners will most likely respond to the differential in fee collections when fees are low, as overtime is most likely to be eliminated when the PTO's financial health is in jeopardy. If this is the dominate mechanism, then low-level officials would be acting in a self-interested manner, but the aggregate result would mimic a benevolent-but-resource-constrained agency. 
granting decisions. We then set forth various testable hypotheses regarding how the Agency will alter its granting decisions in response to these marginal incentives. ${ }^{69}$

\section{A. Renewal Rates}

Once a patent is issued it does not automatically remain in force for the duration of its twenty-year patent term. ${ }^{70}$ The patentee must take the affirmative step of paying renewal or maintenance fees at three-and-a-half, seven-and-a-half, and eleven-and-a-half years from the date at which the patent issued to assure the patent's enforceability (referred to as four-year, eight-year, and twelve-year maintenance fees in the empirical analysis discussed below). If a patentee fails to pay any of these fees, the invention enters the public domain. ${ }^{71}$ Renewal fees currently account for nearly $30 \%$ of the PTO's patent budget, while the cost to the Agency to maintain a patent is negligible. Thus, such fees are almost exclusively utilized to subsidize other agency activity.

However, not every patent grant generates equal renewal-fee revenue. While maintenance fees do not vary across technology classifications, patentees elect to pay these fees at dramatically different rates across such classifications. ${ }^{72}$ Accordingly, the PTO stands to gain more financially by granting patents in technologies that are likely to be renewed at a higher rate relative to those likely to be renewed a lower rate. ${ }^{73}$ Of course, just because the PTO has this financial incentive does not necessarily mean the Agency will act on it. The latter depends, in part, on the Agency's primary objectives and its needs. The rest of this Section proposes that both a self-interested and a benevolent-but-resource-constrained PTO will grant more patents in

69. Importantly, besides the harms associated with a bias toward granting patents, any distortions in the PTO's granting patterns across technological fields and entity size may likewise distort the allocation of innovation resources in society.

70. This is true only for patents that mature from patent applications filed on or after December 12, 1980. 35 U.S.C. § 41(b) (2006) (listing the duration of a patent's effectiveness and the corresponding fees that the Director may charge "for maintaining in force all patents based on applications filed on or after December 12, 1980"). This date introduced renewal or maintenance fees to the U.S. patent system. Thus, patent applications filed before December 12, 1980, were automatically enforceable until the end of their patent term. See 35 U.S.C. $§ 41(b)$.

71. The late payment of any maintenance fee may be accepted if the delay in payment is shown to have been "unavoidable." 35 U.S.C. § 41(c)(1).

72. Renewal-rate differentials hold across technologies both when categorizing technology in terms of the PTO's own classification system and when using more coarsely defined systems. See supra notes 64-66 and accompanying text.

73. Wasserman, supra note 16 , at 412 . 
technology categories with high renewal rates relative to patents in categories with low renewal rates, albeit for different reasons.

\section{The Self-Interested, Budget-Maximizing PTO}

Given that the PTO is seeking to maximize its budget, how will this differential-renewal-fee incentive affect its granting behavior? At first glance it might not affect it at all. A budget-maximizing PTO will instruct examiners to grant every patent, as the Agency stands to profit on each marginal grant from the possibility of the ensuing maintenance fees, whether the probability of collecting such fees is low or high. ${ }^{74}$ Of course, a self-interested PTO may not adopt such a drastic practice for several reasons, including fear of congressional retribution. ${ }^{75}$ To the extent the PTO believes it can skirt detection, and hence punishment, by adopting a less extreme bias toward allowing patents, then even a self-interested PTO may distort its granting behavior in response to the differential in profits arising from technology-wide variations in renewal rates. A self-interested agency can maximize the fees it stands to collect for a given distortionary bias by focusing this overpatenting tendency on technology categories where it stands to profit the most by granting additional patentstechnology categories with high renewal rates.

Hypothesis 1: Following the adoption of a near fully user-feefunded system, a self-interested PTO will grant patents at an incrementally higher rate for patents within technology categories that generally have high maintenance rates relative to patents within categories that generally have low maintenance rates.

\section{The Benevolent-but-Resourced-Constrained PTO}

As discussed in the previous Part, even a benevolent PTO may bias examiners toward granting patents in an effort to reestablish

74. Examination costs are irrelevant for this marginal profitability assessment given that the PTO must examine those applications that are filed and that such examination costs will have already been incurred at the time the PTO makes it granting decision.

75. Administrative law scholars have long noted that Congress exerts substantial influence over agencies that are funded through discretionary spending, meaning that Congress evaluates their budgetary needs annually during the appropriations cycle. See, e.g., RICHARD F. FEnNo, JR., The Power of the Purse: Appropriations Politics in Congress 291 (1966) ("Once the [Appropriations] Committee's ability to hurt it is recognized, the most obvious way for the agency to ensure a favorable kind of relationship with the Committee is simply to do . . what the Committee tells it to do."); Bruce Yandle, Regulators, Legislators and Budget Manipulation, 56 PUB. CHOICE 167, 178 (1988) ("Budget manipulation is the most effective sanction available to Congress."). 
financial sustainability. However, rather than increase patenting across the board, a benevolent PTO in need of additional funds may also generally instruct examiners to grant relatively more patents in technologies with high renewal rates than patents in technologies with low renewal rates. ${ }^{76}$ Under the assumption of benevolence, the PTO will likely wish to limit the degree to which it distorts its granting decisions away from what is otherwise optimal policy. As a result, a benevolent-but-resource-constrained PTO that is attempting to reach a revenue goal would prefer to satisfy this target by granting a few extra patents in technology categories with respect to which it will profit the most-i.e., those with high maintenance rates-rather than a larger number of extra patents in technology categories with respect to which it will profit the least-i.e., those with low maintenance rates. ${ }^{77}$

Hypothesis 2: Following the adoption of a near fully user-feefunded system and during times at which a benevolent PTO is resource constrained, the PTO will grant patents at an incrementally higher rate for patents within technology categories that generally have high maintenance rates relative to patents within categories that generally have low maintenance rates.

76. This analysis, of course, assumes that the PTO knows it will take at least three-and-ahalf years to generate any of these additional revenues. Accordingly, the Agency must anticipate that its resource constraints will likely be binding over at least a moderately long period of time. Moreover, this analysis also assumes that the current PTO management structure is sufficiently forward thinking, even in light of the limited tenure of PTO directors. The director of the PTO is nominated by the President and approved by the Senate, and thus the director of the PTO changes when the administration in the White House changes. See 35 U.S.C. § 3(a)(1) (2006). Nonetheless, other high-level administrators offer significant continuity to the Agency, as these bureaucrats tend to have long tenures at the Agency. See § 3. For example, Commissioner Stoll, who was commissioner for patents, retired from the PTO at the end of 2011 after twenty-nine years of service to the Agency. Press Release, 11-62, Commissioner for Patents Robert Stoll to Retire from Government Service After 29 Years at the United States Patent and Trademark Office (Nov. 2, 2011).

77. Assume that a benevolent PTO is seeking to generate an additional $\$ 6,800$ in fee revenue at a future date. In order to accomplish this goal, the Agency is considering granting additional patents either in a class that has a $90 \%$ renewal rate or a class that has a $10 \%$ renewal rate. The maintenance-fee income generated, on average, from granting an additional patent in each of these classes is $\$ 6,813$ in the former and only $\$ 757$ in the latter. Thus, in order to meets its revenue target, the PTO can either grant one additional patent in the $90 \%$ renewal patent class or nine additional patents in the $10 \%$ renewal-rate class. This calculation assumes the same renewal rate across all three stages of renewal fees. See 37 C.F.R. $\S \S 1.20($ e)-(g) (2012) (listing renewal fees for three-and-a-half, seven-and-a-half, and eleven-and-a-half years from the date the patent issues of $\$ 980, \$ 2,480$, and $\$ 4,110$ respectively). 


\section{B. Entity Size}

Small-entity status allows independent inventors, small businesses, and nonprofit organizations to pay $50 \%$ reduced patent fees. ${ }^{78}$ As a result, the PTO stands to earn twice the amount of postallowance fees (i.e., issuance and renewal fees) by granting a patent filed by a large entity than by granting a patent filed by a small entity. ${ }^{79}$ Of course, the manner in which the PTO responds to this marginal incentive will likely depend on its baseline objectives. The rest of this Section outlines the reasons for why both a self-interested and a benevolent-but-resource-constrained PTO are likely to grant more patents with large-entity designations relative to patents with small-entity designations.

\section{The Self-Interested, Budget-Maximizing PTO}

Similar to the maintenance-rate factor, a self-interested PTO will be incentivized to always grant patents. Although the Agency stands to earn half as much fee revenue by granting a small-entity patent versus a large-entity patent, the PTO will still collect some fee revenue by granting the former. As discussed above, the Agency is unlikely to adopt such an extreme practice. However, if a selfinterested PTO believes it can avert detection and hence punishment by adopting a less extreme bias toward allowing patents, then the Agency will likely focus this expansionary pressure where it stands to earn the biggest returns-large entities. As a result, a self-interested PTO will grant relatively more patents filed by large relative to small entities.

Hypothesis 3: Following the adoption of a near fully user-feefunded system, a self-interested PTO will grant patents at an incrementally higher rate to patent applicants with large-entity status, relative to those with small-entity status.

\section{The Benevolent-but-Resourced-Constrained PTO}

A benevolent PTO that is resource constrained will grant more patents in an effort to increase revenue. However, desiring to minimize deviations from optimal patent policy, the PTO is likely to

78. 35 U.S.C. $\S 41(\mathrm{~h})$. A "small" entity is defined by the PTO as individuals, nonprofit corporations, or corporations that qualify as small businesses under the Small Business Act. 37 C.F.R. $\$ 1.27(a)(1)-(3)(2012)$.

79. Wasserman, supra note 16 , at 412 n.129. 
focus its granting bias on those patents where it stands to profit the most by issuing an additional patent. Accordingly, when a benevolent PTO is bound by financial constraints, it will grant more patents to applicants with large-entity status, relative to those with small-entity status.

Hypothesis 4: Following the adoption of a near fully user-feefunded system and during times at which a benevolent PTO is resource constrained, the PTO will grant patents at an incrementally higher rate to patent applicants with large-entity status, relative to those with small-entity status.

\section{DATA AND METHODOLOGY}

\section{A. Data Sources and Key Variables}

In order to investigate the manner in which the PTO responds to the incentives posed by its fee structure, it is necessary to acquire data on the PTO's granting patterns covering a sufficiently long period of time and covering a broad array of patent types. For these purposes, we filed Freedom of Information Act requests to the PTO and obtained a previously unavailable, comprehensive annual data set on PTO patent-processing outcomes for every utility patent application that was received at the PTO over the sample period. ${ }^{80}$ More specifically, the patent-processing data contains annual patent filings, allowances, and disposals, disaggregated by patent class and entity size. ${ }^{81}$ The

80. For the purposes of this empirical analysis, we focus only on utility patents, especially considering that maintenance fees do not apply to design or plant patents. See 37 C.F.R. $§ 1.20$ (2012).

81. In the data received by the PTO, disposals include patent applications that have been allowed and abandoned. Abandoned patent applications include patent applications that have been rejected and patent applications that have been abandoned for business reasons. Curiously, a patent applicant can elect to "restart" the patent examination process of an application that has been rejected by filing a request for continued examination ("RCE") or by filing a continuation application. By restarting the patent examination process, a "finally rejected" patent application receives continued examination by the PTO. The PTO data includes a finally rejected patent application if an applicant subsequently files a continuation application in its disposals. In contrast, the data does not include a finally rejected patent application if an applicant subsequently files an RCE in its disposals. Most likely, this difference in accounting results from the fact that a patent applicant who files a continuation application files an entirely new application, whereas a patent applicant who files an RCE is requesting continued prosecution of the existing application. Mark A. Lemley \& Kimberly A. Moore, Ending Abuse of Patent Continuations, 84 B.U. L. REV. 63, 68 n.14 (2004). As a result, we control for RCE filings to alleviate concerns that some patent types are better able to secure ultimate allowances through greater usage of RCEs. See infra Section IV.E and Appendix B.

In addition, the PTO appears to have little to no financial incentive to encourage the filing of continuations. The fees for examining an RCE are set below the examining fees for a new 
sample collected spans the time period from 1983 to 2010 . On average, over our sample period, 258,883 patent applications were filed each year, 132,181 patents were allowed each year, and 189,660 patent applications were disposed of each year. Previous investigations on the PTO's granting patterns have utilized an alternate source that allows for the calculation of PTO grant rates across patent types from only 2001 onwards. ${ }^{82}$ Our data allows for the calculation of annual PTO grant rates across patent types spanning the period of 1983 to the present, which in turn makes possible the exploration of the influence of the 1991 fee reform on the PTO's granting behavior.

More specifically, we use these data to calculate patent grant rates specific to given technology-year combinations (e.g., for genetic patents in 1995) and specific to given technology-year-entity-size combinations. Consistent with the PTO's own representation of its granting practices, we calculate grant rates as the number of patents granted by the PTO divided by the number of patent applications disposed of by the PTO. ${ }^{83}$ We categorize technology groups in various ways throughout this analysis. In our primary specifications, we utilize the technological subcategories (delineating thirty-seven different technology groups) specified by Bronwyn Hall, Adam Jaffe, and Manuel Trajtenberg and developed for the Patent Data Project of the National Bureau of Economic Research. ${ }^{84}$

application, and the fees for examining a continuation application are the same as a new application. 37 C.F.R. $\S 1.17$ (e) (2012) (showing that in the fiscal year of 2010 the examination fees for an RCE were $\$ 810$ for a large entity and $\$ 405$ for a small entity). While the PTO acknowledges that the cost of examining a continuing application are, on average, less than the costs of examining an original application, the savings do not reach the amount required to align fees with costs. See U.S. Patent \& Trademark Office, Detailed Appendices: Patent Fee PROPOSAL 1, 61 (2012), available at http://www.uspto.gov/aia_implementation/fee_setting__ppac_hearing_appendices_7feb12.pdf (showing that the PTO estimates the historical cost of examining RCE is approximately \$1700); see also Wasserman, supra note 16, at 409-10 (noting that "the mismatch in examination fees and examination costs for a patent application are likely to increase with each iteration through the examination system").

82. See, e.g., Lemley \& Sampat, supra note 11, at 187-89.

83. See, e.g., European Patent Office, Japanese Patent OfFice, Korean Intellectual Property Office \& U. S. Patent Office, Four Office Statistics Report 2010 (2010), available at http://www.trilateral.net/statistics/tsr/fosr2010/annex2.pdf. Table A2 of Appendix B demonstrates the robustness of the empirical results to the use of alternative grant-rate constructions. See also supra note 81 (describing the data received by the PTO).

84. Bronwyn H. Hall et al., The NBER Patent-Citations Data File: Lessons, Insights, and Methodological Tools, in Patents, Citations, \& Innovations: A Window On The Knowledge ECONOMY 403, 434-37 (Adam B. Jaffe \& Manuel Trajtenberg eds., 2002). The PTO classifies patents into nearly five hundred different technology classes. This classification scheme, however, changes somewhat over time as new classes are added or as others are divided. These compositional changes (particularly divisions) potentially complicate an empirical analysis that tracks within-category changes in PTO behavior over time. For these reasons (and to facilitate a 
We then merge these data on grant rates with data on technology-specific maintenance rates, which capture the likelihoods that patents issuing within the relevant category will be renewed by the patentee at the respective four-year, eight-year, and twelve-year marks following their issuance. ${ }^{85}$ The primary empirical specifications estimated below focus on differentiating across technology categories based on the likelihood of renewing patents at the four-year mark; however the empirical results are robust to alternative approaches that focus on eight-year or twelve-year rates or on some combination of the three rates, as demonstrated by Table A2 in Appendix B. Appendix A provides further details on the construction of the estimation sample and of the relevant variables employed in the empirical analysis.

Table 1 presents descriptive statistics for the key variables used in the regression analysis. The PTO has granted or allowed roughly $70 \%$ of the total patents that it has disposed of over the sample period. ${ }^{86}$ Applications from inventors with small-entity status represent roughly $29 \%$ of the total number of application filings. Roughly $85 \%$ of those patents eligible for renewal at the four-year mark, in fact, renewed their patents. In Appendix A, we provide a breakdown of the maintenance rates and incidence of small entities for each technology category. This breakdown evidences meaningful variation in renewal rates across categories, providing support not only for the methodological framework discussed below, which relies

more manageable regression framework), in our preferred specifications we group patents into the relatively coarser technology classification system set forth by Hall, Jaffe, and Trajtenberg. As demonstrated by Table A2 of Appendix B, however, the results are nearly identical when using regression specifications based on the PTO classifications themselves. In any event, this approach may constitute a more appropriate specification to the extent that the PTO elects to differentiate its granting practices (as hypothesized) at a relatively coarser level. Moreover, if the PTO does indeed differentiate all the way to the PTO classification level, any such differential response should still be observable at the more aggregated level assuming some amount of correlation of profitability characteristics (e.g., maintenance rates) across PTO classes within National Bureau of Economic Research ("NBER") subcategories, as is borne out by the data.

85. For each patent issued following September 1, 1981, the PTO collects detailed log data on all maintenance events for the relevant patent, including, for example, the payment of its four-year renewal fee or the termination of the patent for the failure to pay its due four-year renewal fee. See Patent Maintenance Fees (.zip) and Description Files (.txt) (September 1, 1981 Present), U.S. PAT. \& TRADEMARK OFF., https://eipweb.uspto.gov/MaintFeeEvents (last modified Oct. 25, 2012) (providing publically available data).

86. As the data received by the PTO includes a finally rejected patent application if an applicant subsequently files a continuation application as a disposal, our grant rates do not represent the chances that an originally filed application will issue. Importantly, our analysis does not depend on this calculation, as we are interested in studying the influence of the PTO's fee structure on its granting behavior, not the chances an originally filed application will be allowed. 
upon this variation, but also in the predicted sensitivity of PTO grant rates to its fee structure. ${ }^{87}$

TABLE 1: MEANs AND STANDARD DEVIATIONS OF SELECTED VARIABLES

(1)

Panel A. Averaged Across Patent Category / Year Combinations

Patent Grant Rate (\%, Allowances / Disposals)

Patent Allowances (1,000's)

Four-Year Maintenance Rate (\%)

Eight-Year Maintenance Rate (\%)

63.48

Twelve-Year Maintenance Rate (\%)

Small-Entity Status Rate (\%, Small-Entity

Applications / Total Applications)

\section{Panel B. Aggregate PTO Measures, Averaged Across Years}

Fee-Diversion Policy (\% Incidence)
50.00

(50.92)

0.40

$(0.11)$

Standard deviations are in parentheses. Descriptive statistics are from a sample of 1,058 technology category / year cells from 1983 to 2010 in Panel A and from a sample of twenty-eight years in Panel B. The statistics presented in Panel A are weighted by the relevant number of patent disposals associated with each category-year cell, while those in Panel B are unweighted. The definition of each variable is set forth in greater detail in Appendix A.

87. See infra Table A1 in Appendix A (demonstrating the average maintenance rates across each of the thirty-seven technological categories considered in this empirical analysis). Averaging over the entire sample period, four-year maintenance rates, for instance, span from roughly $69.5 \%$ at the lowest to $93.4 \%$ at the highest. 
Likewise, grant rates demonstrate a meaningful level of variation across technology categories and across years, with a standard deviation of 13.7 relative to its mean of 70.2 (with over $30 \%$ of this variation reflecting changes in grant rates within patent categories over time). ${ }^{88}$ How much of this variation can be explained by the imposition of the PTO's current fee structure and by variations in the PTO's financial strength? We now turn to an explanation of the methodological approach undertaken to investigate these questions.

\section{B. Methodology}

\section{Difference-in-Difference Analysis}

In order to statistically tease out the relationship between the PTO's fee structure and its grant rates, we embrace the existence of a "natural experiment" made possible by the Omnibus Reconciliation Act of 1990, which became effective in 1991. This reform resulted in a roughly $70 \%$ increase in the fees assessed by the PTO and, for the first time, left the PTO essentially fully funded by user fees. ${ }^{89}$ By observing the PTO's granting practices before and after a reform that put into place its current funding structure, we hope to gain an understanding of how this structure affects the foremost decision with which the Agency is tasked: whether or not to grant a patent.

Of course, simply observing the change in overall PTO grant rates before and after this reform in an effort to explore the impact of the reform would be highly problematic. Grant rates are almost certain to change over time for reasons unrelated to the financial incentives facing the PTO-e.g., changes in the quality of underlying applications. Indeed, the predictions set forth in Part II do not dictate that the PTO's grant rates will, in an absolute sense, clearly increase subsequent to the fee reform and during times of strongly binding financial constraints. Rather, the theory predicts that the PTO's grant rates will be higher than they otherwise would be absent the presence

88. It is technically this within-class variation in grant rates over time that is the target of our regression analysis. By including what are called category "fixed effects" we allow for completely fixed differences in grant rates over time across the categories. We ask whether grant rates increase following the 1991 reform within our treatment categories, subtracting out the corresponding within-category changes in grant rates for the control categories (e.g., low maintenance rate categories) in order to isolate the effect of the fee reform.

89. Prior to this time, the PTO met roughly half of its obligations through the collection of user fees. U.S. Patent \& Trademark Office, Annual Report, Fiscal Year 1992, at 53 tbl.2 (1993). 
of the fee reform and/or the financial constraints. ${ }^{90}$ The possibility that other factors may drive grant rates leaves it difficult statistically to disentangle the marginal influence of the fee-structure reform from the impact of changes in these other factors over time (absent observable data on all such other factors). To surmount this problem, we utilize a "difference-in-difference" estimation approach (implemented via regression analysis) that is commonly employed by policy evaluation studies in the economics and law and economics literatures.

The essential premise behind the difference-in-difference approach is to observe how grant rates change before and after the 1991 reform for a set of patents with respect to which the PTO is not likely to exhibit an expansionary responsiveness between grant rates and fee structure (e.g., those with low maintenance rates). To the extent that the grant rates associated with patents of this latter type are likewise impacted by those unobservable drivers of PTO behavior, one can view this set of patents as a "control" group. As such, one can effectively use the change in grant rates around the 1991 fee reform for this control group as an estimate for the influence of the change over time in these unobservable drivers. Thereafter, one can subtract this estimate from the corresponding estimate of the change in grant rates before and after the 1991 reform on the set of patents for which one would expect a responsiveness between grant rates and fee structure-i.e., the treatment group. This calculation should provide us with the desired disentangling of factors and thus leave us with an unbiased estimate of the true impact of the reform itself on PTO granting practices.

To execute this empirical approach and to form the necessary treatment and control groups, we draw on the theoretical predictions from Part II regarding which types of patents are associated with grant rates that are more or less likely to be sensitive to fee structure. Embracing each of the predictions set forth in Part II, we test for various differential responses to the 1991 reform across different types of patents-e.g., across large and small entities. Under the

90. For instance, if other, unrelated factors are driving a downward trend in PTO grant rates, the theory predicts that the influence of fees and/or financial constraints may cause that trend to be less severe than it otherwise would be. Moreover, even if, in absolute terms, grant rates are not rising over time, it may still be the case that the marginal increase in patent grant rates that otherwise does ensue from these fee influences could be detrimental to innovation policy. After all, such influences could be disrupting what is otherwise a rational and optimal downward trend in granting policies. The focus of this Article is on that marginal, fee-related distortion itself. 
fundamental assumption that, absent the reform, each patent type would have continued along the same trajectory (not necessarily at the same level, though), this exercise allows us to evaluate the general motivating question of this Article: does the PTO distort its granting practices in an expansionary manner in response to its fee-based incentives?

It is worth emphasizing that this approach accounts for the possibility of completely fixed differences in grant rates across patent types-i.e., inherent differences across types that are present across all sample years. After all, to use entity size as an example, our analysis is not simply comparing large- and small-entity grant rates. Rather, we are comparing how the change in large-entity grant rates before and after 1991 compares to the corresponding change in smallentity grant rates before and after 1991. As such, by focusing on this difference-in-difference calculation, we allow for the possibility that there is something fundamentally unique about the granting likelihoods facing large entities relative to small entities (i.e., the possibility that large entities garner a higher grant rate than small entities because the former has access to higher-quality attorneys or because the former has better internal screening mechanisms regarding the patentability of their inventions). It is also worth emphasizing that this empirical exercise does not rule out the possibility of other Agency-level and examiner-level biases in behavior (e.g., examiner biases ensuing from their compensation structure). Rather, the design is simply meant to isolate the particular bias stemming from the Agency's fee structure.

In reality, the empirical specifications that we estimate below are a bit richer than the simple difference-in-difference description set forth above, though that description does capture its key intuitions. In Appendix A we provide more details regarding the precise empirical specifications that we estimate. For instance, rather than forming one treatment group and one control group, many of our empirical approaches consider a continuum of patent types (e.g., differentiating technology categories based on a measure of their four-year maintenance rates) and then observe how the PTO's practices respond to the 1991 reform as we move along this continuum. ${ }^{91}$

91. While numerous examples exist, the primary empirical precedent that we follow in this Article is Daron Acemoglu and Amy Finkelstein's investigation into the differential change in the capital-labor ratio of hospitals following the national adoption of the Medicare Prospective Payment System (PPS) in 1984, where hospitals are differentiated (and theorized to respond differently to the adoption of PPS) based on their pre-reform share of Medicare patient days. 
Of course, while the difference-in-difference approach holds the promise of isolating the marginal effect of the PTO's fee structure on its grant rates, it does rely on various assumptions and thus carries various caveats. For instance, if those separate patent types that are predicted to be responsive and nonresponsive, respectively, to the patent fee structure already happen to be on divergent trends in their granting patterns prior to the fee reform, then the basic difference-indifference results may be picking up the influence of these preexisting trends, as opposed to the influence of the reform itself. Fortunately, we will be able to look for various markers of this potentially confounding story, as will be discussed in the results section below. More generally, in a series of so-called "specification checks," we challenge the various assumptions underlying the baseline empirical approaches and demonstrate the flexibility and the robustness of the findings to a range of alternative approaches.

\section{Financial-Sustainability Analysis}

Our regression analysis exploits sources of variations beyond that of mere time (before and after 1991) and patent type (e.g., large vs. small entity). Integral to our empirical analysis is also the consideration of variations over time in the degree to which the PTO is bound by its financial constraints and likely to be in need of additional sources of revenue. As predicted in Part I, under the assumption of benevolence, the PTO may only be expected to respond to fee incentives by granting differentially across patent types during times in which such constraints are binding. In order to test this prediction, we modify the basic regression approach discussed above and effectively explore whether the primary difference-in-difference finding is itself likely to emerge to a stronger degree during times in which markers indicative of PTO revenue need are more prevalent. For these purposes, we draw upon the theory set forth in Part I, whereby we predicted that the PTO would be more likely to trigger its sustainability constraint upon a change in various factors, including an increase in its backlog, a decrease in its annual renewal-fee collections, an increase in the average complexity of its examinations, and a decrease in the proportion of large-entity patentees. Each such development would disrupt any financial balance reached and decrease the proportion of incoming fees to outgoing costs.

Daron Acemoglu \& Amy Finkelstein, Input and Technology Choices in Regulated Industries: Evidence from the Health Care Sector, 116 J. POL. ECON. 837 (2008). 
In Table A8 of Appendix B, we estimate regressions that explore how fluctuations over time in each of these separate factors are associated with a differential grant rate across the delineated patent types. Of course, in any given year, all of these factors are changing at the same time, even though the PTO is only subject to a single sustainability constraint. In other words, in a given year, the PTO may experience an X\% increase in its backlog, which will leave it more likely to face break-even concerns, along with a Y\% increase in aggregate renewal rates, which will leave it less likely to face such concerns. These separate regressions alone leave us unable to determine how to weigh the respective influences of each such development upon the PTO's aggregate financial strength and thus upon its ultimate decisionmaking. Therefore, in our primary approach to testing this sustainability prediction, which we undertake in Part IV below, we combine these factors into a composite sustainability measure. This "sustainability score" is constructed so as to capture the impact of these factors on the PTO's financial balance in a manner consistent with the empirically relevant influence of each such factor. To this end, we use actual data on the annual fluctuations in the above factors (e.g., annual maintenance rates, backlog levels, etc.), along with information on the parameters of the PTO's fee schedule, to simulate an annual measure equal to the ratio between (1) the issuance and post-issuance fees generated by the existing stock of patents at a given point in time and (2) the net costs associated with the examinations demanded of the PTO at that time. ${ }^{92}$ Appendix A provides further specifics regarding this calculation. A higher simulated sustainability score is suggestive of fewer financial pressures facing the PTO and thus less need of additional funds.

In calculating this sustainability metric, we proxy the examination demand facing the PTO in a given year by the PTO's backlog of patent examinations at that time. ${ }^{93}$ Of course, the PTO does

92. This calculation also draws upon information on the history of patent issuances over time, which bears, for instance, on the number of patents up for renewal during the given year. In rough terms, multiplying these numbers by the annual renewal rates and by the associated renewal fees allows us to estimate the amount of issuance and post-issuance fees that were made available to the PTO during the given year. See infra Appendix A.

93. Using annual disposal counts to proxy for this demand is less preferred considering that disposals are under the PTO's control and could be seen as a reflection of the PTO's response to the demands it faces, as opposed to a reflection of the underlying, external cost pressures being placed upon the PTO. In rough terms, we estimate the net costs associated with all of the examinations demanded upon the PTO for a given year by multiplying the backlog by the average costs of examination for that year, where this average is influenced by the distribution of applications across the various examination complexity levels for that year (that is, certain technologies are allocated more hours of examination and thus carry greater 
not need to examine its entire backlog each year. Nonetheless, it might be reasonable to assume, especially considering the PTO's own rhetoric, ${ }^{94}$ that the Agency is nonetheless motivated by its mission to increase disposals in the face of a large and growing backlog. As such, the calculated sustainability score may provide a sense of the ease by which the PTO may use its stream of incoming funds to satisfy the substantial costs associated with all of those examinations presently awaiting the PTO.

This exercise of exploring whether the PTO's distortionary practices are more pronounced during times of greater financial need allows for an appropriate specification of the PTO's predicted behavior under the benevolent model. At the same time, this approach also allows us to shed light on an ongoing debate in administrative law regarding the nature of government employees: are PTO bureaucrats acting in self-interest to universally expand the Agency's budget or are PTO bureaucrats acting with optimal innovation policy in mind, though occasionally bound to distort the Agency's behavior in pursuit of required resources?

\section{RESULTS}

The regression results presented in Table 2 illuminate and test the key hypotheses presented in Part II above. Generally, these hypotheses set forth that the PTO's fee structure causes it to increase the rate at which it grants patent types that generate higher back-end fees relative to the rate at which it grants patent types that generate lower back-end fees. This differential analysis sheds light on the broader and more fundamental question motivating this paper: does the PTO's fee structure create a bias toward granting patents? We begin in Panel A of Table 2 with an analysis of the PTO's differential

examination costs, in which event average examination costs for a given year depend upon the distribution of applications across technologies for that year). See infra Appendix A (offering more detail). The sustainability score is not meant to reflect the actual profits accruing to the PTO in a given year. Rather, it is meant to simulate how variations in the above-mentioned factors (keeping all other factors fixed) affect its general profitability. That is, it provides a meaningful and empirically relevant way of assessing the relative contributions to the PTO's financial position-i.e., its balance of incoming fees to outgoing costs—of each of these factors. If the backlog happens to grow by $40 \%$ over a given year, while annual renewal rates increase by $5 \%$ over that year, this calculation allows for an appropriately greater emphasis to be placed upon the backlog growth in assessing the PTO's need for funds.

94. 2011 PERFORMANCE AND ACCOUNTABILITY REPORT, supra note 31, at 112 (stating that the Inspector General's top management challenges facing the PTO include "reducing the patent application backlog"); 2010 PERFORMANCE AND ACCOUNTABILITY REPORT, supra note 2, at 3 ("The Agency continues to face operational challenges including . . . a large backlog."). 
response to its fee structure across technology categories with varying renewal rates. ${ }^{95}$

\section{A. Difference-in-Difference Results: Renewal Rate Specifications} hypotheses:

To recap, in Part II, we set forth the following testable

Hypothesis 1: Following the adoption of a near fully user-feefunded system, a self-interested PTO will grant patents at an incrementally higher rate for patents within technology categories that generally have high maintenance rates relative to patents within categories that generally have low maintenance rates.

Hypothesis 2: Following the adoption of a near fully user-feefunded system and during times at which a benevolent PTO is resource constrained, the PTO will grant patents at an incrementally higher rate for patents within technology categories that generally have high maintenance rates relative to patents within categories that generally have low maintenance rates.

\section{Primary Difference-in-Difference Results}

The results presented in Panel A of Table 2 are consistent with the general prediction that the PTO would, following the adoption of a fully user-fee-funded system, grant at an incrementally higher rate to patents within high-maintenance-rate categories relative to those within low-maintenance-rate categories. The coefficient estimate presented in Column 1 of Panel A captures the relationship between the PTO's grant rate and the interaction between being in the postreform period ("REFORM") and being in a high-maintenance-rate category ("MAINTAIN"). More specifically, the estimated figure of 58.96 suggests that the impact of the 1991 reform on the PTO grant rate is fifty-nine percentage points higher (or roughly $84 \%$ higher) for a patent category with a maintenance rate of $100 \%$ than it is for a category with a $0 \%$ maintenance rate and likewise, 5.9 percentage

95. As discussed in Part III above, we classify patents into the thirty-seven technological subcategories set forth by Hall, Jaffe, and Trajtenberg, supra note 84. As demonstrated in Table A2 of Appendix B, however, the pattern of results presented in Table 2 remains virtually unchanged when we use alternative classification schemes, including the more fine-grained PTO Classification System and the broader six-category-level system likewise introduced by Hall, Jaffe, and Trajtenberg. 
points higher for a category with a maintenance rate of $X \%$ relative to one with a rate of $X-10 \% .{ }^{96}$

This latter interpretation-i.e., the 5.9 percentage-point differential-is perhaps a more meaningful description of the findings considering that technology categories simply do not differ by 100 percentage points in their maintenance rates. ${ }^{97}$ The standard deviation in four-year maintenance rates across technology categories (unweighted) is roughly six percentage points, with a low maintenance rate of roughly $62 \%$ (amusement devices) and a high of roughly $94 \%$ (semiconductors). ${ }^{98}$ The underlying regression estimated in Panel A explores the differential response to the 1991 reform along a linear continuum of maintenance rates (by interacting the binary reform variable with a continuous maintenance-rate measure). In Table A4 of Appendix B, we relax the assumption of linearity and estimate a less parametric specification that assigns technology categories dichotomous (0/1) variables for being in different quartiles (e.g., top

96. We do not begin the sample period used in the maintenance-rate regressions until 1987. By that time frame, both the PTO and the industry players will have acquired some experience with the renewal payment process (maintenance fees originated with patents issued at least after September 1981). This will allow us to evaluate how the steady-state experience of a PTO with a renewal system in place responds to the 1991 fee reform. One might be concerned that the reflection on the initial experience with maintenance fee payments led to certain immediate behavioral changes that impacted relative grant rates across high-renewal and low-renewal technology groups. For instance, consider a technology that is inclined to renew at a low rate. Upon the imposition of the renewal system, one might expect that this industry would begin to file applications at marginally lower rates, focusing this reduction on low-quality applications. A response of this nature, in light of a more selective application pool, could lead to the observation of a jump in grant rates for low renewal-rate technologies relative to high renewal-rate technologies. This response may occur both during the initial imposition of the renewal system and subsequently following the first experience with the renewal payment decision itself. In fact, the data do suggest a pattern of this nature at both such times. The results of our analysis are entirely robust to beginning our sample period in these earlier years. Of course, the 1991-feereform results are not likely to be severely jeopardized by this initial response to the maintenance-fee-paying experience considering that this initial response ran counter to the predicted response of the 1991 fee reform and could thus not serve as a competing explanation for our primary results. In any event, to avoid this initial calibration and to more cleanly identify the impact of the fee reform of interest, we elect to begin the sample in the period of time after all parties have had the opportunity to experience at least a year or two of the renewal payment process.

97. Panel A simply interprets the findings along such drastic extremes considering that the MAINTAIN variable is defined in fractional terms (thus ranging from 0 to 1 in value) and that coefficients of regressors are typically interpreted as the change in the dependent variable associated with a one-point change in the regressor.

98. This range is based on the preferred specification of the 4-year maintenance rates, which are determined according to the average rates experienced across technology categories up to 1990. See infra Appendix A. As such, this range differs slightly from that reported in Table A1 (see infra Appendix A), which reports average maintenance rates experienced over all sample years. 
$25 \%$, bottom $25 \%$, etc.) of maintenance rates. We find a roughly 6.8 percentage-point differential grant-rate response to the 1991 reform between technologies in the top and bottom quartiles of maintenance rates.

TABLE 2. THE IMPACT OF PTO FEE REFORMS ON GRANT RATES: PRIMARY DIFFERENCE-IN-DIFFERENCE REGRESSION COEFFICIENTS (2) (3) (4)

Panel A. Differential Impact of Fee Reform Across Patent Categories with Varying Maintenance Rates (unit of observation: Category / Year; dependent variable: category-year-specific grant rate)

\begin{tabular}{lcccc}
\hline REFORM * MAINTAIN $_{\mathrm{i}}$ & $58.96^{* * *}$ & $170.41^{* * *}$ & $104.50^{* * *}$ & $125.78^{* * *}$ \\
& $(19.16)$ & $(47.16)$ & $(28.63)$ & $(45.67)$ \\
REFORM * MAINTAIN & & & \\
SUSTAINABILITY & - & $-290.18^{* * *}$ & - & -77.68 \\
& & $(92.37)$ & & $(126.20)$ \\
REFORM * MAINTAIN & & & & $-70.29^{* * *}$ \\
DIVERSION & - & - & $(18.38)$ & $-57.09^{* *}$ \\
& & & & $(23.83)$ \\
Number of observations & 887 & 887 & 887 & 887 \\
\hline
\end{tabular}

Panel B. Differential Impact of Fee Reform Between Patents with Large- and SmallEntity Status (unit of observation: Category / Year / Entity Size; dependent variable: category-year-entity-size-specific grant rate)

\begin{tabular}{lcccc}
\hline REFORM * LARGE & $6.44^{* * *}$ & $21.92^{* * *}$ & $12.20 * * *$ & $17.39 * * *$ \\
& $(1.61)$ & $(4.36)$ & $(2.37)$ & $(4.33)$ \\
REFORM * LARGE $*$ & & & $-19.24 * *$ \\
SUSTAINABILITY & - & $-40.82^{* * *}$ & - & $(9.46)$ \\
REFORM * LARGE $*$ DIVERSION & - & $(8.44)$ & & $-9.27^{* * *}$ \\
& & - & $(1.77)$ & $(1.87)$
\end{tabular}

\footnotetext{
Number of observations 1843 1843 1843 1843

* significant at $10 \%$; ** significant at 5\%; *** significant at $1 \%$. Standard errors are reported in parentheses and are clustered to correct for autocorrelation within patent categories over time (Panel A) and for autocorrelation within patent-category / entity-size combinations over time (Panel B). All regressions include patent-category fixed effects and year fixed effects to control for fixed differences in grant rates across patent categories and across years, respectively. Regressions in Panel B include entity-size fixed effects as well. Regressions are weighted by the number of disposals used to form each observation's grant rate. Data on patent-processing statistics and maintenance rates were obtained from the PTO.
} 
Under an assumption that the PTO's granting patterns for high-maintenance-rate categories would otherwise have trended in the same manner as for low-maintenance-rate categories absent the reform (though still allowing for inherently fixed differences in grant rates across technologies), the estimated difference-in-difference findings can be interpreted as an expansionary effect of the fee reform itself and thus of the user-fee-funded fee structure imposed by the reform. In other words, the above estimate can be treated as causal in nature under an assumption that there are no unobservable "shocks" to the PTO's granting practices that are specific to high-maintenancerate categories in the post-1991 period. We relax, and further explore the validity of, this assumption in various ways in Section D and Appendix B below. For instance, among others things, we demonstrate that the PTO had not already begun these differential granting patterns during the period of time prior to the reform, a finding that would have otherwise raised concerns that some unobservable factor other than the reform is responsible for the findings.

Of course, observing the differential response to the fee reform across technologies with different renewal rates does more than simply allow us to tell a potentially causal story (under the above assumptions). This differential response represents immediate policy concerns in its own right. That is, by possibly inducing the PTO to extend preferential treatment to some technologies over others, the PTO's fee structure may be undesirably distorting the allocation of resources across different sectors of the economy.

\section{Sustainability-Interaction Results}

According to the theory set forth in Parts I and II, a selfinterested PTO aiming to either maximize its budget or its profits would always be expected to act upon the incentives created by its fee structure. On the other hand, our model suggests that a benevolent PTO would only elect to grant additional patents in an effort to earn extra revenues during periods of time in which it is likely to be resource constrained. As such, to more completely test the predictions of the benevolent-PTO model, we modify the empirical specifications estimated in Column 1 to interact the primary difference-in-difference variable with a metric (i.e., the sustainability score described in Part III) capturing the likelihood that the PTO is on strong financial ground.

The coefficient on this interaction variable-i.e., in Panel A of Table 2, the REFORM * MAINTAIN * SUSTAINABILITY variable- 
provides us with an indication of whether the differential grant-rate response to the 1991 reform between high- and low-maintenance-rate categories is itself likely to be greater during periods of time in which the PTO is subject to heightened financial sustainability concerns. A greater differential response of this nature would be identified by the estimation of a negative coefficient on this interaction variable considering that the sustainability score is defined such that a higher score entails a stronger financial position of the PTO. Consistent with this prediction, we estimate that as the sustainability score increases by 0.1 (or roughly a $25 \%$ improvement in the financial position of the PTO), the differential response to the 1991 reform between a $100 \%$ maintenance-rate category and a $0 \%$ maintenance-rate category is itself expected to fall by roughly twenty-nine percentage points.

While Column 2 explores whether the differential response to the fee reform is stronger during times of more financial stress, we also estimate empirical specifications that de-emphasize the 1991 reform and that directly specify a difference-in-difference analysis based only on variations over time in the PTO's financial sustainability score, focusing only on the post-1991-reform period. That is, we also estimate specifications that test whether the PTO begins to grant patents at an incrementally higher rate to highmaintenance-rate technologies relative to low-maintenance-rate technologies as the PTO experiences a change in conditions that leaves it more likely to face sustainability concerns. One, of course, needs some variation in the PTO's fee structure to statistically tease out the impact of that structure. This alternative conceptualization of the basic difference-in-difference design is premised on the idea that we may gain a better understanding of the impact of the PTO's fee structure by exploring variations in the conditions under which the PTO would even be sensitive to that structure in the first place.

We present results of this alternative specification of the primary difference-in-difference approach in Table A6 of Appendix B. The findings completely match those of Column 2 in suggesting that the PTO is more likely to distort its behavior when it is in greater need of funds. For instance, we estimate that, as the sustainability score decreases by 0.1 (representing a 25\% decline in the PTO's financial sustainability position), the PTO begins to grant patents at a 29.2 percentage-point higher rate for patents within a technology category with a maintenance rate of $100 \%$ relative to patents within a category with a $0 \%$ maintenance rate. This finding can likewise be interpreted as an effect ensuing from the PTO's fee structure under an assumption that there are no unobservable shocks to the PTO's grant 
rates for high-maintenance-rate technologies that coincide with declines in the PTO's financial health.

All told, it appears that the PTO is not universally seeking to expand its revenues in response to the incentives created by its userfee-funded structure. Rather, it may tend to use its granting practices as a revenue-generating tool only when necessary to sustain itself. We demonstrate this finding more clearly and on a year-to-year basis in Section $\mathrm{D}$ below in discussing the results of a dynamic difference-indifference regression. In addition to confirming the predictions of the benevolent-but-constrained PTO model, these findings likewise shed light on the initial and more fundamental question of whether the PTO is indeed self-interested or benevolent in motivation, arguably providing support for those theories that have challenged the Niskanen model. ${ }^{99}$

Accordingly, the findings presented in Panel A of Table 2 do not lend support to Hypothesis 1, in so far as they are generally inconsistent with the characterization of the PTO as being a selfinterested, budget-maximizing agency. However, the findings are consistent with Hypothesis 2 in suggesting the PTO's fee structure induces the Agency to grant at an incrementally higher rate to highrenewal-rate technologies.

\section{B. Difference-in-Difference Results: Entity-Size Specifications}

To recap, in Part II, we set forth the following testable hypotheses:

Hypothesis 3: Following the adoption of a near fully user-feefunded system, a self-interested PTO will grant patents at an incrementally higher rate to patent applicants with large-entity status, relative to those with small-entity status.

Hypothesis 4: Following the adoption of a near fully user-feefunded system and during times at which a benevolent PTO is resource constrained, the PTO will grant patents at an incrementally higher rate to patent applicants with large-entity status, relative to those with small-entity status.

\section{Primary Difference-in-Difference Results}

Similar to the maintenance-rate results discussed above, the results presented in Panel $\mathrm{B}$ of Table 2 are consistent with the

99. See supra Section I.B.1. 
prediction that the PTO would respond to the adoption of a fully userfee-funded system by granting at an incrementally higher rate to patent applicants with large-entity status, relative to those with small-entity status. ${ }^{100}$ The coefficient estimate reported in Column 1 of Panel B suggests that the 1991 fee reform is associated with a 6.4 percentage-point higher grant rate for large entities relative to small entities. Considering a mean grant rate of $70 \%$ over the sample period, this corresponds to a roughly $9 \%$ higher grant rate for large entities. ${ }^{101}$ As above, under an assumption that large and small entities would have otherwise followed a similar trend over time absent the reform (though, still allowing for completely fixed differences in granting patterns between large and small entities), this finding is suggestive of an effect of the reform itself and thus of a bias toward granting additional patents induced by the Agency's fee structure.

In finding that the 1991 reform is associated with a preferential grant rate for large entities, which pay double the fees of small entities, we provide general support for the contention that the PTO's fee structure induces a bias toward granting patents. As with the maintenance-rate results, this differential response also raises policy concerns of its own and suggests that the effect of extending lower fees to small entities may be to undermine the very purpose of that fee differential in the first instance-i.e., to foster innovation among small firms and individual entrepreneurs. ${ }^{102}$

100. While this underlying regression considers differences in grant rates over time (before and after 1991) and across entity sizes (large and small), it also includes technology-specific fixed effects. See infra Appendix A (providing further discussion). By accounting for fixed and inherent differences across technologies (and knowing grant rates at a level specific to given years, entity sizes, and technologies), we can alleviate concerns that the estimated findings are attributable to a scenario in which the incidence of large-entity patentees increases over time within technology categories that happen to experience higher grant rates historically.

In late 1982, Congress, for the first time, set differential fees based on small- versus largeentity-size distinctions. Act of Aug. 27, 1982, Pub. L. No. 97-247, § 1, 96 Stat. 317. This discount for small entities was eventually made permanent. Act of Nov. 6, 1986, Pub. L. No. 99-607, § 1(b)(2), 100 Stat. 3470 (codified as amended at 35 U.S.C. § 41(h) (2006)). Accordingly, we set 1986 as the beginning of the sample period for the small-entity regressions; however, the results remain virtually unchanged when we begin the estimation sample in 1983.

101. See also infra Table A2 in Appendix B (finding virtually identical results for this entitysize interaction coefficient when we include controls for maintenance rates at the entity-sizecategory-specific level, confirming that the estimated differential granting trend between large and small entities following the 1991 reform is likely a result of the higher (i.e., double) fees ensuing from the large-entity status and not a result of the possibility that large entities also happen to maintain their patents at higher rates).

102. See supra note 15 and accompanying text. 


\section{Sustainability-Interaction Results}

Consistent with the maintenance-rate results, we likewise find that as the sustainability score increases (representing an improvement in the PTO's financial status), the differential response to the 1991 reform between large and small entities falls, as evidenced by the negative estimate of the coefficient on the REFORM* LARGE* SUSTAINABILITY interaction term presented in Column 2 of Panel B. Again, this suggests that the PTO may not be universally increasing its grant rates in order to maximize fee revenues. Rather, it appears that the PTO distorts its behavior so as to increase grant rates to large entities (which generate higher fees) to a greater degree during times in which the PTO is in greater need of funds. ${ }^{103}$

Accordingly, as with the maintenance-rate findings, the results presented in Panel B of Table 2 do not lend support to Hypothesis 3, in so far as they are generally inconsistent with the characterization of the PTO as being a self-interested, budget-maximizing agency. However, the findings are consistent with Hypothesis 4 in suggesting the PTO's fee structure induces the Agency to grant at an incrementally higher rate to high-renewal-rate technologies.

\section{Interactions with Fee-Diversion Policy}

As indicated in Part I above, between the years of 1991 and 2003, the PTO was subject to policies that effectively forced it to share a portion of its anticipated fee collections with Congress, an event that is often labeled as "fee diversion." The practice of fee diversion and the consequent division of anticipated collections with Congress may blunt the incentives of the PTO to increase its grant rates in an effort to generate greater revenues. Consider the year 2002, for instance. While the PTO projected it would collect roughly $\$ 1.35$ billion over that year, Congress only authorized a budget of $\$ 1.05$ billion. ${ }^{104}$ Accordingly, Congress's inclinations to limit the PTO's funding availability in 2002, in turn, may have likely left the PTO less inclined to push Congress

103. See also infra Table A6 in Appendix B (estimating an alternative difference-indifference specification that focuses only on the post-1991 period and simply explores whether the PTO increases its grant rate to large entities relative to small entities during times in which the PTO faces greater financial pressures-i.e., during times in which its sustainability score falls). Again, the estimates of this exercise match those of the results presented in Column 2 of Panel B, which interact the fee-reform-based difference-in-difference variable with the sustainability score.

104. See supra note 28. 
for an even higher budget that year and thus less inclined to seek an expansion in its grant rates to justify a higher budget.

Following 2004, on the other hand, Congress neither automatically diverted a percentage of the fees collected (as it did between 1991 and 1998) nor capped the PTO's budget at an amount less than its anticipated collections (as it did between 1999 and 2003). Rather, the PTO's spending authority was capped at its projected revenue stream, thereby maintaining a possible incentive of the PTO to seek an expanded grant rate during those years and a correspondingly higher anticipated revenue amount. We test these predictions in Column 3 of Table 2. Similar to the sustainabilityinteraction specifications, we explore whether the differential response to the 1991 reform across different patent types is, in turn, weaker during those years (i.e., 1991-2003) in which a stronger feediversion policy was in place. Consistent with these expectations, the results presented in Column 3 suggest that during periods of a strong fee-diversion policy relative to a weak one, there will be a smaller feeinduced divergence in PTO grant rates across varying maintenancerate categories and between large and small entities. ${ }^{105}$ While the practice of fee diversion may be undesirable from a number of policy perspectives, it may nonetheless blunt the grant-related distortions that arise from the PTO's user-fee-funded structure.

\section{Dynamic Difference-in-Difference Regression Results}

Our empirical specifications allow for completely fixed differences in grant rates across years and patent categories (in Panels A and B) and likewise across entity-size specifications (in Panel B). However, a concern arises that the primary difference-indifference result is merely reflective of a preexisting differential granting trend between, for instance, large and small entities, as opposed to being attributable to an actual effect of the fee reform itself. To help rule out this possibility, we estimate dynamic difference-in-difference regressions, which modify the approaches taken thus far to now interact the categorical distinctions in patent

105. In Column 4 of Table 2, we attempt to disentangle the fee-diversion and sustainability stories by including both sets of interactions in the same regression, an exercise complicated by the significant collinearity between these two factors. While the estimated coefficients of the interaction terms fall in magnitude and precision, the findings remain suggestive that the differential granting patterns induced across patent types by the 1991 reform are themselves likely to vary both as a result of fee diversion and as a result of the PTO's actual need for additional funds. 
types with a set of dichotomous variables representing each year in the sample (as opposed to simply a dichotomous variable for being in the post-1991 period). We present the results of these dynamic regressions in Figures 1 and 2. For each year of the sample, we report the $95 \%$ confidence bands of the coefficient on the interaction between that year and the differential grant rate of interest (e.g., between large and small entities in Figure 2). The coefficient values are interpreted with reference to 1991, where the differential grant rate across patent types is normalized to zero in 1991. More simply, the results of this dynamic exercise can be interpreted as the time trend in the differential grant rates across technology categories with high and low maintenance rates (Figure 1) and between large and small entities (Figure 2), where these differential rates are scaled such that they equal zero in 1991.

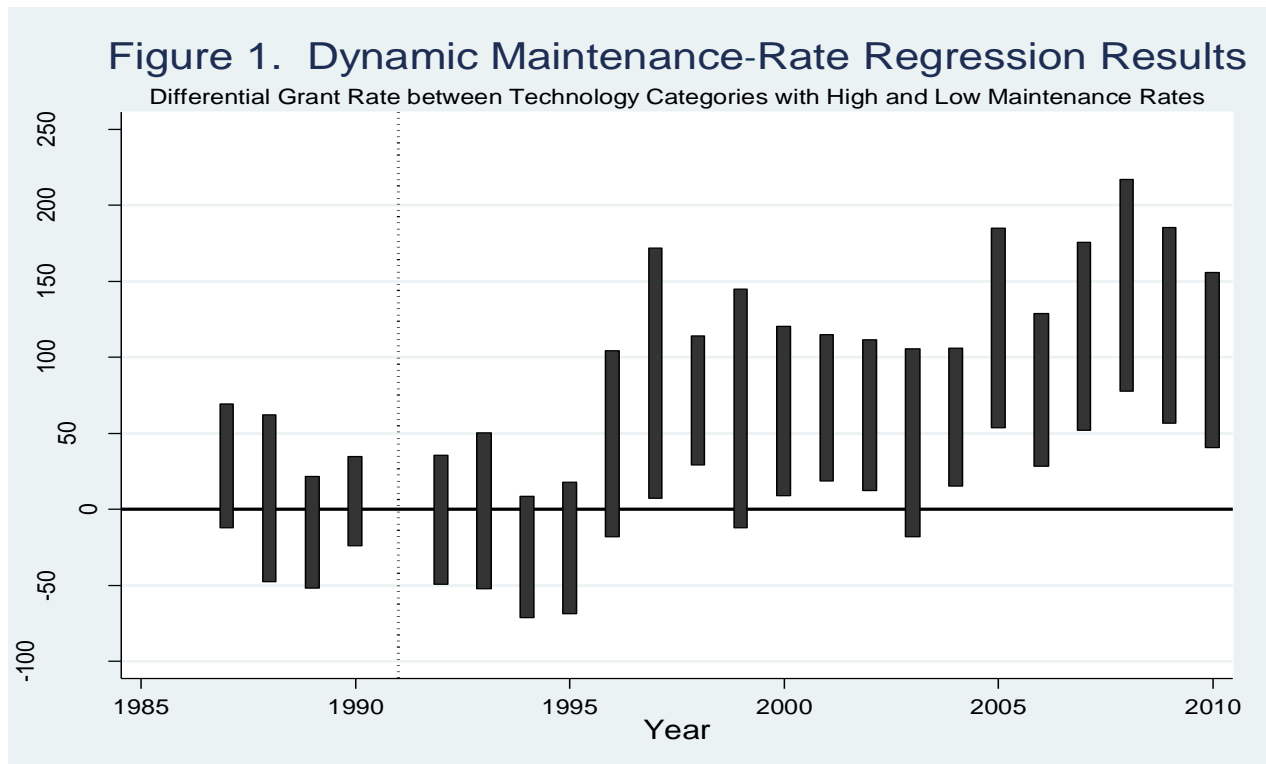

Note: the bars represent 95\% confidence intervals for the estimated coefficients of a dynamic difference-in-difference regression specification that interacts the category-specific maintenance-rate variable with indicator variables representing each year in the 1987-2010 period. This collection of estimated dynamic coefficients can be interpreted as a time trend in the differential granting periods between patent categories with high maintenance rates relative to low maintenance rates. This differential is normalized at zero in 1991, representing the reference year. Each regression includes category and year fixed effects. Patent-processing and maintenance data are from the PTO. 


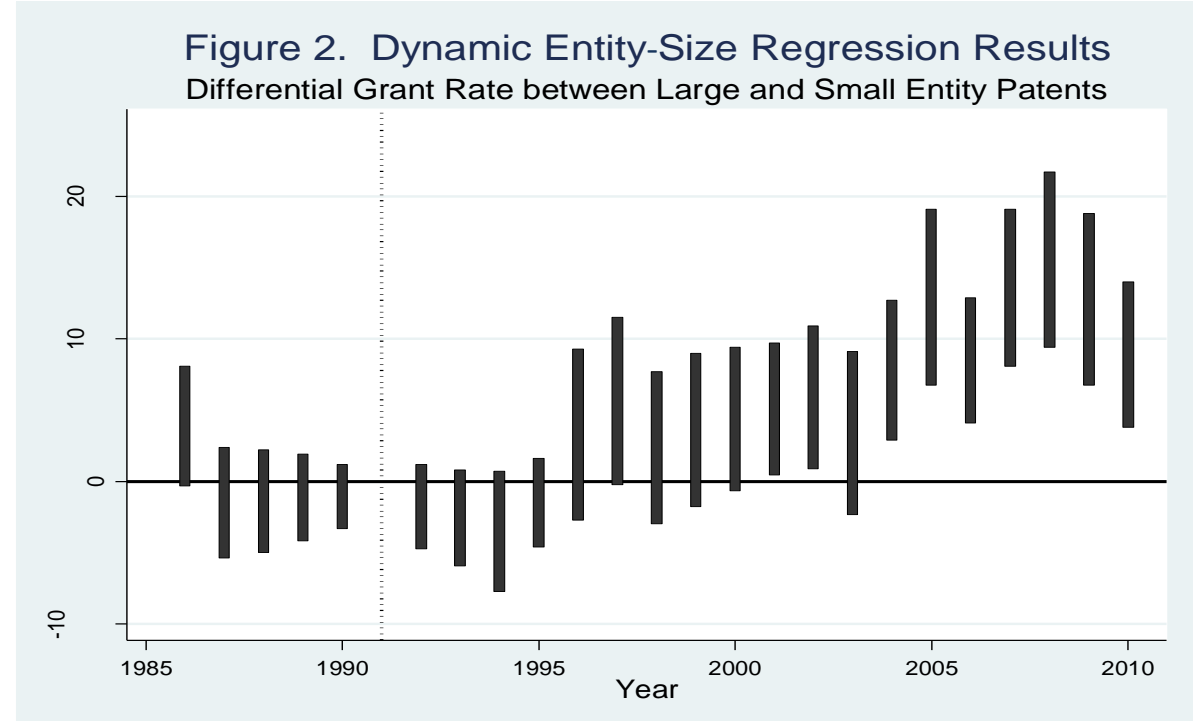

Note: the bars represent $95 \%$ confidence intervals for the estimated coefficients of a dynamic difference-in-difference regression specification (with a unit of observation at the category-year-entity-size level) that interacts the large-entity-size status indicator with indicator variables representing each year in the 1986-2010 period. This collection of estimated dynamic coefficients can be interpreted as a time trend in the differential granting periods between large and small entities. This differential is normalized at zero in 1991, representing the reference year. Each regression includes category and year fixed effects. Patent-processing and maintenance data are from the PTO.

This dynamic approach allows us to explore the evolution over time in the relevant differential granting patterns. As can be observed in each of Figures 1 and 2, there appears to be no discernible trend in the direction of the expected reform effect in the pre-1991 period, easing any concerns that the main results in Table 2 are reflective of preexisting differential trends likely attributable to factors other than the reform.

Of course, there remains a concern that unobservable factors emerging in the post-1991 period are responsible for the observed patterns-e.g., unobserved "shocks" in the grant rates of highmaintenance-rate categories in the post-1991 period. We appease these concerns in various ways in Appendix B. For instance, in Table A3, we demonstrate the robustness of our results to the inclusion of various observable control variables (which are only available in the pre-2005 period-e.g., forward-looking citation counts). We also 
estimate a so-called "triple-differences" regression that explores whether the differential maintenance-rate result is itself stronger with respect to large entities within those high-maintenance-rate categories (under an assumption that a benevolent PTO wishing to minimize its distortionary practices as much as possible would focus its distortionary efforts on the highest fee generators-i.e., largeentity patents within high-maintenance-rate classes). As explained in further detail in Appendix A, this "triple-differences" specification allows us to rule out the confounding influence of a larger range of unobservable factors, including those that are specific to given technology-year combinations and to given entity-size-year combinations. Accordingly, this specification addresses concerns over unobservable "shocks" in the grant rates of large entities and highmaintenance-rate categories in the post-1991 period. Indeed, as demonstrated by Table A5 of Appendix B, we find evidence suggesting that the divergent grant rates between high- and low-maintenancerate categories is itself more concentrated in large entities within those categories than small entities, providing general support to the findings presented in Table 2.

To complement these dynamic figures, in Figure 3, we plot the time trend in the PTO's sustainability score, overlayed with the trend in the differential grant rates between large and small entities (reporting the means of the coefficients displayed in Figure 2, represented in fractions). As demonstrated by this figure, consistent with the interaction results of Table 2, the degree to which the PTO elects to grant patents at a relatively higher rate to large entities (presumably to earn higher revenues) appears to be highly correlated with a deterioration in the Agency's financial position-represented by a reduction in the PTO's sustainability score-during the period of time following the imposition of the fully user-fee-funded system (while not shown, a similar correlation becomes apparent with the differential grant rates across technologies with high and low maintenance rates). This correlation is apparent over the long horizon and even with respect to several of the short-term spikes and dips in the sustainability score (e.g., 1994, 2005, 2006, and 2009). The graph also evidences an apparent correlation between the distortionary granting practices and a relaxation of the relevant fee-diversion policies in the post-2003 period.

While not shown, we likewise calculate an alternative sustainability score that uses the backlog of applications awaiting a first office action by the Agency (using annual data received from the PTO pursuant to a Freedom of Information Act request), as opposed to the total backlog of applications awaiting completion of examination. 
Arguably more correlated with the commencement of this upward trend in the differential grant rates between large and small entities, this alternative sustainability measure, though nearly identical to the one presented in Figure 3, begain its downward decline in 1995, as opposed to 1997.

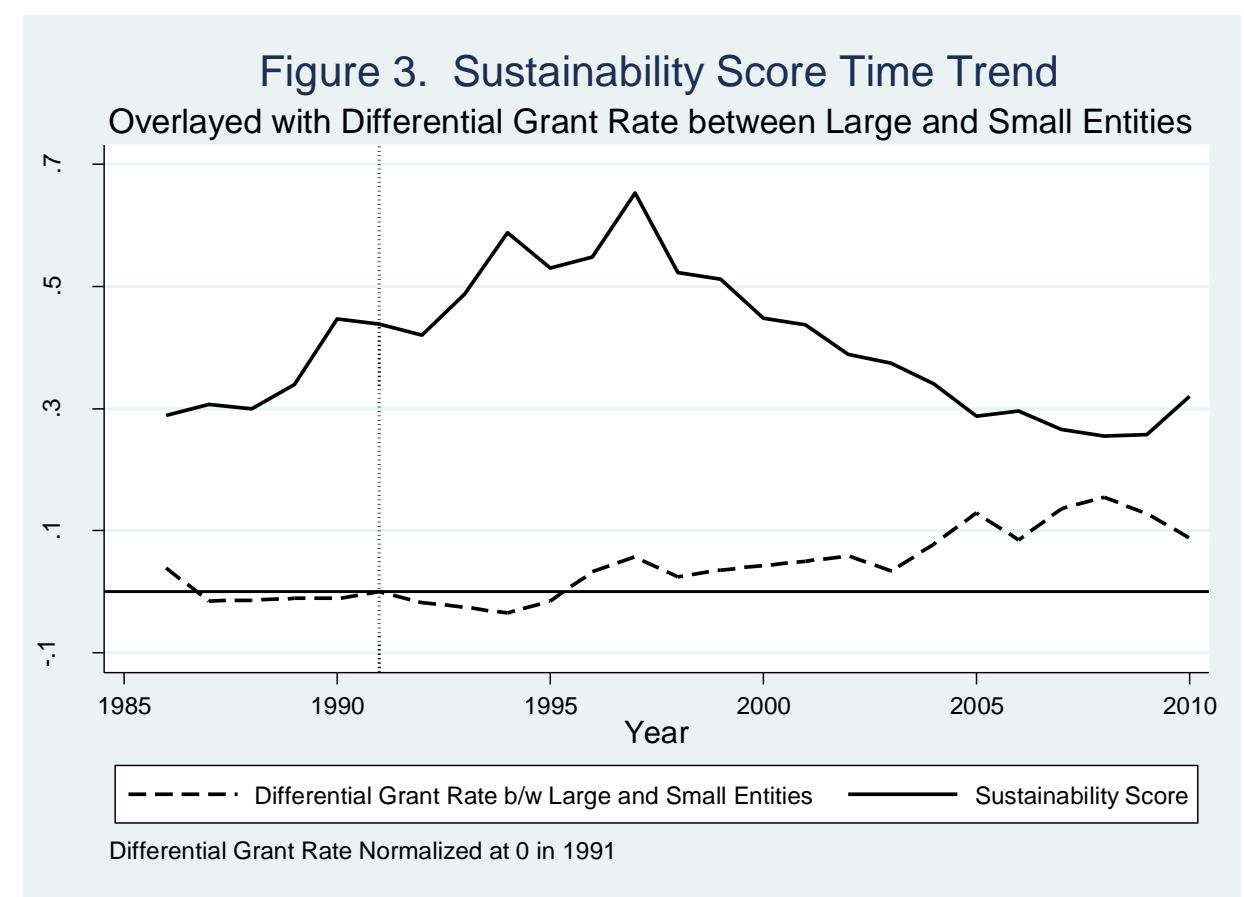

As evidenced by Figures 1 and 2, the divergent responses to the 1991 reform emerge with a several-year lag following 1991. This lag may be reasonable under an assumption that it takes the PTO some time to adjust its granting practices under the new fee regime. More likely, perhaps, this lag may be attributable to the fact that markers indicative of financial sustainability are particularly strong during the 1992 to 1995 period, as demonstrated by Figure 3. The PTO may have experienced a financial boost over this short time period considering that it began to collect the substantial twelve-year maintenance fees for the first time during these years. ${ }^{106}$ Ultimately, the results from these dynamic exercises lend further support to Hypotheses 2 and 4.

106. 1994 ANNUAL REPORT, supra note 35, at 29 ("In the fiscal year 1994, the PTO was just beginning to receive the full effects of the third stage renewal."). The PTO saw a substantial jump in renewal-fee income in the fiscal year 1994. Compare id. at 59 (noting that $32 \%$ of patent fee collections resulted from maintenance fees), with U.S. PAT. \& TRADEMARK OFFICE, ANNUAL 


\section{E. Robustness / Specification Checks}

There is a potential concern that selection effects due to changes in the filing behavior among small and large entities following the 1991 fee reform may be responsible for the observed differential trends in the PTO's granting behavior. Two selection-effect scenarios in particular could potentially explain the observed differential trends in grant rates. First, large entities or patent applicants in high-renewal groups may file relatively fewer patent applications post-1991 than pre-1991. This response could implicate a possible concern that a selected sample of higher-quality applications remained, resulting in the PTO granting more patents with respect to large entities and high-maintenance-rate categories. Because the 1991 reform that modified the funding structure at the Agency level also carried a substantial increase in the fees charged to applicants, it is possible that applicants responded to this increase by reducing their filings ${ }^{107}$ (potentially to a higher degree among large entities and among those in high-maintenance-rate categories, considering the higher expected fees).

Second, small entities or patent applicants in low-renewal groups may file relatively more patent applications after the 1991 reform than before. This response would also implicate a concern that a selected sample of applications are driving our results; however, this selected sample would be of lower, not higher, quality. Both the post1991 enactment of programs at the PTO to assist small entities ${ }^{108}$ and the rise of the "patent troll" or the nonpracticing entity, ${ }^{109}$ could possibly result in small entities increasing their filings. We appease both of these concerns in Table A7 of Appendix B and demonstrate that the 1991 reform did not lead to either a reduced (and possibly more-selective) large-entity or high-renewal-rate applicant pool or an increased (and possible less-selective) small-entity or low-renewal-rate applicant pool in the post-1991 period. More specifically, if anything, it appears that the 1991 reform is associated with an incrementally

REPORT, FISCAL YEAR 1993, at 34 fig.9 (1994) (noting that 26\% of patent fee collections resulted from maintenance fees).

107. There is some support for a modest sensitivity of patent demand to fees. See generally Gaetan de Rassenfosse \& B. van Pottelsberghe de la Potterie, On the Price Elasticity of Demand for Patents, 74 OXFORD BULl. ECON. \& STAT. 58, 58-77 (2011).

108. For example, the PTO began hosting an annual Independent Inventor Conference in 1995. See Press Release, U.S. Patent \& Trademark Office, Fifth Annual Independent Inventors Conference (Sept. 26, 2000), available at http://www.uspto.gov/news/pr/2000/00-55.jsp.

109. See, e.g., Mark A. Lemley, Are Universities Patent Trolls?, 18 Fordham InTELl. Prop. MEDIA \& ENT. L.J. 611, 630 (2008) (describing generally the rise of the patent troll). 
higher rate of filing for large entities relative to small entities and for high-maintenance-rate technologies relative to low-maintenance-rate technologies. ${ }^{110}$

A potential concern likewise arises that certain developments in substantive patent law may be responsible for the observed differential trends in the PTO's granting behavior. For instance, this may occur if the law expands what constitutes patentable subject matter within technologies that happen to have high maintenance rates or high concentrations of large-entity applicants. Patent scholars have noted that patent-eligible technology has expanded largely to include inventions in the field of biotechnology, software, and business methods. ${ }^{111}$ However, most of the legal developments of this potentially expansionary nature with respect to biotechnology occurred in the early- to mid-1980's prior to the estimation sample frame. ${ }^{112}$ While the mid- to late-1990's likewise experienced expansions in patentable subject matter that likely targeted software and business method patents, ${ }^{113}$ the above results are not a reflection of these developments, as demonstrated by Table A2 in Appendix B. The estimates remain virtually unchanged when we remove those technology categories implicated by the relevant legal developments.

Another possible concern arises that the divergent grant rates across the various patent types are a response to the passage of the Trade-Related Aspects of Intellectual Property Rights ("TRIPS") agreement in 1995. Considering the variation in category-specific examination times, one of the effects of TRIPS (which modified the

110. Furthermore, a decrease in sustainability score (and thus an increased need of funds) is associated with an incrementally higher rate of filing for high-maintenance-rate technologies relative to low-maintenance-rate technologies. Finally, there is no signifigant evidence to suggest that a decrease in sustainability score is associated with an incrementally higher filing rate for small relative to large entities, which could pose troubling selection concerns. See also infra Appendix B (generally discussing the robustness of the above findings to the possibility of compositional changes in applicants among the delineated patent types).

111. See, e.g., Wasserman, supra note 16, at 381 (describing the "dramatic expansion of the scope of patentable subject matter").

112. See Diamond v. Chakrabarty, 447 U.S. 303, 305 (1980) (holding that "human-made, genetically engineered bacterium" is patentable subject matter); see also Policy Statement on the Patentability of Animals, 1077 Off. Gaz. Pat. \& Trademark Office 24 (Apr. 21, 1987), reprinted in Donald S. Chisum, 9 Chisum On Patents app. 24-1 (2005) (“[T]he Patent and Trademark Office now considers nonnaturally occurring, nonhuman multicellular living organisms, including animals, to be patentable subject matter.”).

113. See, e.g., State St. Bank \& Trust v. Signature Fin. Grp., 149 F.3d 1368, 1373 (Fed. Cir. 1998) (enlarging patent subject matter to include anything that provides a "useful, concrete, and tangible result”), abrogated by In re Bilski, 545 F.3d 943 (2008); Proposed Examination Guidelines for Computer-Implemented Inventions, 60 Fed. Reg. 28,778, 28,778 (proposed June 2, 1995). 
patent term from seventeen years from issuance to twenty years from application) was to increase the effective patent length for some technology categories relative to others. ${ }^{114}$ One might argue that TRIPS induced those patents in the larger-expansion categories to file higher-quality applications in the post-1995 period, resulting in a higher grant rate. To the extent that such categories are correlated with those that also maintain their patents at high rates or that have strong large-entity representations, the possibility of this TRIPS story may confound the above analysis. In Table A2 of Appendix B, we address these concerns by demonstrating that the regression results presented above are robust to the inclusion of control variables capturing a differential response to being in the post-1991 period (or, in the alternative, in the post-1995 period) across technology categories with different examination prosecution times (i.e., with different patent-duration increases expected under TRIPS). ${ }^{115}$

In Appendix B (primarily in Table A2), we further demonstrate the robustness of the findings reported in Table 2 and in Figures 1-3 to an additional range of specification checks. These exercises largely demonstrate the flexibility of the above results to the use of various alternative approaches in either specifying the key analytical variables or in specifying the empirical model itself. More specifically, we discuss the robustness of the findings to:

- the inclusion of control variables capturing the intensity of usage of requests for continued examinations ("RCE") and their predecessors (i.e., continuing prosecution applications (“CPA")), to alleviate concerns that some patent types are better able to secure ultimate allowances through greater usage of these mechanisms;

- the systematic, one-by-one exclusion of each technology category from the regression specification (along with the exclusion of each patent class and broad (six-level) category) to demonstrate that no single technology (broadly or narrowly defined) is driving the results;

114. David S. Abrams, Did TRIPS Spur Innovation? An Analysis of Patent Duration and Incentives to Innovate, 157 U. PA. L. REV. 1613, 1615 (2009).

115. Likewise, we also estimate the main difference-in-difference specifications for two different sets of patent categories: (1) within the top $25 \%$ of patent categories based on the expected duration increase associated with TRIPS and (2) within the bottom $25 \%$ of patent categories based on the expected TRIPS-related patent duration increase. We actually find a stronger divergent response to the 1991 fee reform for patents within the latter set of patent categories, suggesting that the overall findings are not likely driven by TRIPS as opposed to the fee reform. 
- alternative constructions of the PTO grant rate (and the use of natural logs of all such rates);

- the inclusion of various category-year-specific control variables;

- the simultaneous (as opposed to separate) treatment of maintenance-rate, entity-size, and examination-cost stories;

- the specification of the 1991 reform variable as a postreform linear-trend variable, ${ }^{116}$ along with the subsequent inclusion of technology-category-specific linear time trends;

- the classification of technology categories based on (1) the PTO Classification System and (2) the broad sixcategory classification scheme alternatively introduced by Hall, Jaffe, and Trajtenberg; ${ }^{117}$

- the estimation of a "triple-differences" empirical specification that explores whether the divergence in patent grant rates across high- and low-maintenancerate categories is itself stronger for large (relative to small) entities within those categories;

- the use of a more flexible randomization-inference approach to the determination of the statistical significance of the estimates;

- the specification of the fee reform based on the percentage of the Agency's funding attributable to user fees; and

- less parametric specifications of those factors, such as category-specific maintenance rates, that are treated linearly in the main regressions.

\section{F. Results Summary and Implications}

Collectively, the above findings provide consistent and robust evidence of:

- an association between the 1991 reform and a divergence in granting patterns between patent applications filed by large versus small entities;

- an association between the 1991 reform and a divergence in granting patterns between patent

116. See Finkelstein \& Acemoglu, supra note 91, at 855-56.

117. See supra note 84. 
applications associated with high- versus low-renewalrate categories;

- a stronger association of the above nature during times when the PTO is more likely to be bound by financial sustainability constraints; and

- a stronger association of the above nature during times in which the PTO is subject to a less stringent feediversion policy.

As discussed above, our results have a number of implications for both policy and theory. ${ }^{118}$ First, from a social welfare perspective our results are discouraging. Under the assumption that the PTO's grant rates would otherwise reflect the optimal balance between dynamic innovation-stimulation incentives and static consumer welfare costs, any marginal increase in patent granting attributable solely to the Agency's funding structure may implicate potentially substantial social welfare costs. ${ }^{119}$ From a policy perspective, our results also suggest that the 50\% reduction in patent fees to small entities may have the inadvertent effect of biasing the PTO toward granting patents associated with large enterprises. As a result, it is possible that the PTO's response to the fee differential may end up leaving small entities worse off than before this special status was created. On a theoretical level, our results are also relevant to the ongoing debate in administrative law regarding the nature of governmental employees. Our finding that the PTO's granting distortions are more likely to occur when markers indicative of an underfunded PTO are present contradicts the idea that bureaucrats are budget maximizers while lending support to the notion that when agencies seek enlarged budgets they do so as a result of being mission minded but resource constrained.

\section{IMPLICATIONS AND REDUCING THE PTO's FINANCIAL INCENTIVE TO GRANT PATENTS}

Beyond the implications already discussed, our results are also relevant to the recently passed America Invents Act. This section begins by exploring the implications of our findings to the America Invents Act and then turns to sketch two possible mechanisms for reducing PTO bias toward granting patents: eliminating the Agency's

118. See supra Part I.

119. See supra notes 7-9 and accompanying text. 
self-financing requirement and changing the fee structure of the Agency.

\section{A. Implications of the America Invents Act}

The results presented in this Article have implications for at least two changes brought forth to the patent system by the America Invents Act ("the Act"), which represents the most significant modification to the patent system since 1952. Our findings cast doubt on whether the provisions of the Act that create a new status of microentity and provide this entity with reduced patent fees will fulfill their legislative intent of nurturing innovation by individual inventors, ${ }^{120}$ similar to doubts that have arisen as to whether congressional action attempting to support small entities seeking patents has achieved its desired result. Our results suggest that under the historic fee schedule, the fee reduction provided to microentities will likely have the undesirable effect of biasing the PTO toward granting patents filed by large entities. Just as with small entities, it is possible that the alleged benefits that microentities obtain by paying reduced patent fees may be outweighed by the harms they experience in the marketplace because the PTO is extending preferential treatment toward large enterprises.

Second, our results should help to allay some of the concerns voiced by those who opposed the sections of the Act that granted the Agency's fee-setting authority. Several groups objected to giving the PTO the ability to set its fees out of fear that the Agency would act in a self-interested and imperialistic manner-for example, dramatically increasing its fees and decreasing its productivity. ${ }^{121}$ Our findings that the PTO's behavior is more consistent with the model of benevolence than self-interestedness suggest that the PTO is more likely to restructure its fees to recover its aggregate costs while continuing or

120. Leahy-Smith America Invents Act, Pub. L. No. 112-29, § 10(g), 125 Stat. 284 (2011) (codified at 35 U.S.C. $§ 123$ (2011)) (requiring micro entities to have not filed more than four previously filed patent applications at the PTO and to have a gross income that does not exceed three times the medium household income as reported by the Bureau of the Census); see also H.R. REP. No. 112-98, pt. 1, at 50 (2011) (describing Congress's intent to spur innovation among independent inventors).

121. See, e.g., Letter from Douglas Norman, President, Intellectual Prop. Owners Ass'n, to John Conyers \& Lamar Smith, U.S. Congressmen (May 17, 2010), available at http://www.ipo.org/AM/Template.cfm?Section=Home\&TEMPLATE=/CM/ContentDisplay.cfm\&C ONTENTID=25867 ("[W]e are concerned that placing fee-setting authority with the USPTO will lead to large declines in productivity and large increases in fees in the longer term."). 
expanding its current productivity than set its fees in a manner to clandestinely maximize its budget. ${ }^{122}$

\section{B. Reducing the PTO's Financial Incentives to Grant Patents}

Currently, our findings suggest that the inadequacies of the examination fees and the existence of post-allowance fees may bias even a benevolent PTO toward granting patents. Our results also suggest that this bias is most likely to manifest with respect to patent grants that the PTO stands the most to profit from-patents with a high likelihood of being renewed and patents associated with large entities. The PTO's granting distortions could be eliminated by removing the Agency's ability to use post-allowance fees as a mechanism to raise revenue. We explore two different approaches to this end: funding the Agency, at least partially, from direct appropriations and restructuring the PTO's fee schedule.

The PTO's financial incentive to grant patents may be decreased and possibly eliminated by financing the Agency, at least partially, from tax revenue. If the Agency's funding does not scale directly with its revenue collection, the PTO's financial incentive to grant patents could be substantially curtailed. Our findings that the PTO's granting bias is dampened during fee diversion support this contention. However, we are concerned that Congress may fail to adequately fund the Agency. Mounting concern regarding deficit containment as well as Congress's past track record of utilizing PTO fees to fund other governmental activity (even when the Agency's financial sustainability was in question) suggest that serious consideration should be given to eliminating the PTO's granting bias by restructuring the Agency's fee schedule.

The PTO has very recently been given the ability to set its fees to recoup its aggregate costs by rulemaking. ${ }^{123}$ As a result, modifying the Agency's fee schedule may be easier today than before the Agency had such authority. ${ }^{124}$ Importantly, any fee schedule adopted must take into account not only the PTO's needs for financial sustainability but also the incentives and social welfare of patent applicants and society. More research is needed on how both the PTO and patent

122. See supra Section IV.B (suggesting that the PTO's behavior reflects an attempt to increase grant rates in an effort to raise additional revenue only when the Agency is financially constrained not in an effort to maximize budget more generally).

123. America Invents Act $\S 10(a)(2)$.

124. At the time this Article was written the PTO had not proposed changes to its examination, issuance, or renewal fees. 
applicants would respond to fee changes, and thus it is beyond the scope of this Article to propose an optimal fee structure of the PTO. ${ }^{125}$ Nonetheless, we believe it is helpful to begin to explore fee structures that are likely to eliminate or dampen the PTO's pro-patentee tendencies identified in this Article.

To begin, the PTO cannot choose to eliminate the fee reductions for small entities and microentities, as this is beyond the scope of its rulemaking authority. ${ }^{126}$ Thus, one way to reduce the PTO's incentives toward granting patents to large entities may be to adopt a fee schedule that curtails the Agency's incentives toward allowing patents in general.

The PTO could dampen its incentives to grant patents by adopting a fee schedule that will align its examination fees with examination costs and/or enacting other pre-allowance fees-i.e., restructuring its fee schedule so that it garners a greater percentage of its budget through pre-allowance fees. Because the PTO is required to set its fee collections to match its operational expenses, an increase in the level of examination fees will likely necessitate a decrease in the level of post-allowance fees. This fee schedule will likely reduce the Agency's tendency to grant patents, because the PTO will be less likely to be constrained by financial sustainability-i.e., the Agency will be less sensitive to dips in the nonbiased grant rate or aggregate renewal fee collections. However, when the Agency's sustainability is triggered, the distortionary bias to grant patents will likely be larger. The PTO will have to grant more patents to meet a revenue target than it would have under its traditional fee structure because the Agency stands to make less money per patent grant than it did under the traditional fee schedule.

Additionally, as long as the Agency is dependent on back-end fees, its pro-patentee tendencies will not be eliminated. The PTO will still have to grant a certain percentage of patents in order for its fee collections to match its operational expenses, and a number of factors will continue to possibly disrupt the Agency's financial equilibrium. ${ }^{127}$

125. Recent studies have shown that, at least with respect to low patent fees, patent demand is relatively inelastic. See de Rassenfosse \& van Pottelsberghe, supra note 106, at 71-72 (finding that the demand for patents is responsive to price, but relatively inelastic); Timothy K. Wilson, Patent Demand - A Simple Path to Patent Reform, 2 InT'L IN-HOUse Couns. J. 806, 81012 (2008) (arguing that filing fees need to be raised significantly in order to reach the elastic portion of the demand curve).

126. It also seems unlikely that Congress will extinguish these fee reductions, as the America Invents Act just created the microentity status.

127. See supra Section I.B.2 (describing factors that may produce imbalance in the ratio of post-allowance fees and operational expenses). 
Of course, the fact that the Agency has recently been granted feesetting authority means the PTO can attempt to reestablish financial equilibrium by changing its fee structure, rather than granting additional patents. However, there are several reasons why the Agency may struggle with utilizing rulemaking to routinely tweak its fee schedule. ${ }^{128}$ First, legislative challenges and procedural requirements associated with rulemaking may increase the cost of the process to such a level that the Agency will not be able to frequently utilize the process to change its fee structure. ${ }^{129}$ Second, to the extent the Agency is facing an impending financial crisis, the PTO may not be able to enact fee increases fast enough to boost its revenue, as the rulemaking process can take years to complete. ${ }^{130}$ Thus, a PTO that is both dependent on back-end fees and facing immediate financial pressures may still turn to granting additional patents in an effort to augment its fee collections.

Perhaps the only way to eliminate a self-sufficient PTO's bias toward granting patents is to abolish post-allowance fees altogether. Under this approach the Agency's examination fees would need to be dramatically increased, and possibly other pre-allowance fees would need to be enacted in order for the PTO's fee collections to cover its

128. It is likely, though, that the PTO will be able to use rulemaking to occasionally change its fee structure.

129. See, e.g., Jerry L. MashaW et al., Administrative LaW, the American Public LaW SYSTEM: CASES AND MATERIALS 617-20 (6th ed. 2009) (describing institutional impediments to rulemaking). The PTO, like many other agencies, has struggled with using rulemaking to implement changes. For example, in 2007 the PTO utilized rulemaking to limit the number of continuation applications as well as the number of claims that could be included within each application. However, the Agency ultimately rescinded the regulations amidst court challenges. See Tafas v. Doll, 559 F.3d 1345, 1349 (Fed. Cir. 2009), vacated, 328 Fed. App’x 658, 658 (Fed. Cir. 2009) (holding that both the claim and continuation rules were procedural in nature and within the Agency's rulemaking authority, but that the continuations rule was inconsistent with patent law); Tafas v. Doll, 328 Fed. App'x 658, 658-59 (Fed. Cir. 2009) (granting petition to rehear the case en banc, vacating the panel opinion); Tafas v. Dudas, 541 F. Supp. 2d 805, 817 (E.D. Va. 2008) (granting summary judgment against the PTO); Tafas v. Dudas, 511 F. Supp. $2 d$ 652, 671 (E.D. Va. 2007) (granting a preliminary injunction preventing the PTO from implementing changes to the continuation practice on the eve of their implementation); Changes to Practice for Continued Examination Filings, Patent Applications Containing Patentably Indistinct Claims, and Examination of Claims in Patent Applications, 72 Fed. Reg. 46,716 (Aug. 21, 2007) (codified at scattered sections of 37 C.F.R. pt. 1) (revising patent rules regarding continuing applications); Press Release, U.S. Pat. \& Trademark Office, USPTO Rescinds Controversial Patent Regulations Package Proposed by Previous Administration (Oct. 8, 2009), available at http://www.uspto.gov/news/09_21.jsp (reporting on the PTO's Final Rule rescinding regulations, providing background on the rules, and reviewing related litigation history).

130. Several agencies have abandoned rulemaking altogether, largely in part due to frustration with the slow pace at which the process proceeds. ROBERTA S. KARMEL, REGULATION By Prosecution: The Securities And Exchange Commission vs. Corporate America 16 (1982) (describing the Securities and Exchange Commission's evolution toward adjudication). 
operational expenses. As the Agency's entire fee stream would derive from pre-allowance activity, the Agency would no longer have a financial incentive to grant patents, because the Agency no longer stands to gain any additional fee revenue from patent grants. While this fee structure would eliminate the pro-patentee tendencies identified in this Article, it is not clear that it would enhance consumer welfare overall. The elimination of maintenance fees would effectively mean that all patents would last their entire term of twenty years, which may substantially increase the static costs of patents to society. Furthermore, depending on how patent applicants would respond to increased fees, patent applications may fall to a level below ideal. ${ }^{131}$ The former concern could be addressed, however, by preserving renewal fees but restricting the amount of renewal fees the PTO can retain. The restricted fees could be utilized to pay a portion or all of the small-entity and microentity subsidy. This funding structure would likely result in dampening the Agency's bias toward issuing patents that are likely to be renewed or that were filed by large entities. Most likely, Congress would need to enact additional changes to the PTO's funding structure in order to achieve this result, but these changes would be minor.

\section{CONCLUSION}

This Article presents the first empirical study of the influence of the PTO's funding on the Agency's decision on whether or not to grant a patent. Our findings suggest that the PTO's current fee schedule likely biases the Agency to grant patents. Moreover, we find the Agency's bias is more likely to manifest with respect to patents that it stands to profit the most from granting-patents that are likely to be renewed or patents filed by large entities. Furthermore, we also find that these distortions are more likely to occur when markers indicative of an underfunded PTO are present.

In addition to their theoretical implications, our findings also speak to policy issues concerning patent law. Prior to our study, commentators failed to recognize the extent to which the PTO's fee schedule biased the Agency toward issuing patents. As a result, recent

131. See supra note 125 (citing sources that illustrate relative inelasticity of patent demand at least with respect to low patent fees). A simple decrease in patent filings does not necessarily have negative social welfare implications. Patent applicants may respond to the increased fees by better sorting patent applications-i.e., filing applications that are more likely to meet the standards of patentability. Companies and individuals may also utilize alternative mechanisms to protect their ideas, such as trade secrecy. 
patent reform, which was enacted in part to address the harms associated with the PTO issuing too many invalid patents, may not eliminate the granting pressure identified in this Article. Moreover, our results have a number of implications for the recently enacted America Invents Act, including the creation of microentity status wherein eligible patent applicants pay $75 \%$ reduced patent fees. Our findings suggest that the fee reductions for microentities are likely to have the unintended consequence of further biasing the PTO toward granting patents to large entities. 